Federal Reserve Bank of Dallas

Globalization and Monetary Policy Institute

Working Paper No. 161

http:// www.dallasfed.org/ assets/ documents/ institute/ wpapers/2013/ 0161.pdf

\title{
Is the $\mathbf{N}$ et Worth of Financial Intermediaries More Important than That of N on-Financial Fims?*
}

\author{
Naohisa Hirakata \\ Bank of Japan \\ Nao Sudo \\ Bank of Japan \\ Kozo Ueda \\ Waseda University
}

October 2013

\begin{abstract}
To explore the relative macroeconomic importance of financial intermediaries' (FIs') net worth to that of non-financial firms (entrepreneurs), we extend the financial accelerator model of Bernanke, et al. (1999), such that both FIs' and entrepreneurs rely on costly external debt. Our model, which is calibrated to the U.S. economy, highlights two features of the FIs' net worth. First, the relative size of FIs' net worth as compared to entrepreneurial net worth, namely, the net- worth distribution in the economy, is important for the financial accelerator effect. Second, a shock to the FIs' net worth has greater aggregate impact than that to entrepreneurial net worth. The key reason for these findings is the low net worth of FIs' in the United States. O ur results imply that the ongoing regulatory reforms that protect banks' net worth from irrational exuberance or foster its accumulation are beneficial for macroeconomic stability.
\end{abstract}

JEL codes: E44

\footnotetext{
* Naohisa Hirakata, Financial System and Bank Examination Department, Bank of Japan, 2-1-1 Nihonbashi, Hongoku-cho, Chuo-ku, Tokyo 103, Japan .naohisa.hirakata@boj.or.jp. Nao Sudo, Financial System and Bank Examination Department, Bank of Japan, 2-1-1 Nihonbashi, Hongoku-cho, Chuo-ku, Tokyo 103, Japan. Nao.sudou@boj.or.jp. Kozo Ueda, School of Political Science and Economics, Waseda University, 1-6-1 Nishi-Waseda Shinjuku-ku, Tokyo 169-8050, Japan. kozo.ueda@waseda.jp. The previous title of this paper was Chained Credit Contracts and Financial Accelerators. The authors would like to thank David Aikman, George Marios Angeletos, Jess Diamond, Tomoyuki Nakajima, Hiroshi Osano, Mathias Trabandt, Wako Watanabe, David Vines, seminar participants at Kyoto University, Otaru University of Commerce, Far East and South Asia Meeting of the Econometric Society, Bank of Canada, Bank of England, and Bank of Italy, and the staff of the Bank of Japan, for their useful comments. In particular, the authors would like to thank Lawrence Christiano and Simon Gilchrist for encouragement at the outset of the research. The views in this paper are those of the authors and do not necessarily reflect the views of the Bank of Japan, the Federal Reserve Bank of Dallas or the Federal Reserve System.
} 


\section{Introduction}

The Great Recession that started in the middle of 2007 underscored the significance of the net worth of the financial sector in many advanced countries, particularly in the United States. Severe deterioration in the net worth of major financial intermediaries (hereafter FIs) led to malfunctioning of the interbank market, widening of various credit spreads, and the subsequent collapse of FIs. Loan supplies to non-financial firms became tight, dampening aggregate output and deteriorating FIs' net worth even further. Not surprisingly, policy responses to the crisis have targeted FIs' net worth. In implementing the Troubled Asset Relief Program, for instance, the U.S. Treasury has purchased assets and equity from financial institutions and attempted to moderate the devastating effects of the financial tsunami.

In contrast, macroeconomic theories before the crisis focused primarily on non-financial entrepreneurial net worth, rather than FIs' net worth. For instance, an influential pioneering work by Bernanke, Gertler, and Gilchrist (1999, hereafter BGG) considers informational friction in credit contracts between FIs and borrowing entrepreneurs, and shows that endogenous developments in entrepreneurial net worth amplify and propagate exogenous shocks hitting the economy, thus acting as a financial accelerator. A subsequent work by Gilchrist and Leahy (2002) based on the same framework demonstrates that a shock to entrepreneurial net worth itself acts as a source of aggregate fluctuations.

In this paper, we outline the role of FIs' net worth in the macroeconomy by using a dynamic stochastic general equilibrium (DSGE) model, built upon the financial accelerator model of BGG (1999). In particular, we ask how the role of FIs' net worth differs from that of non-financial entrepreneurs' net worth. If a difference exists, we single out the economic features of FIs that are responsible for the difference. To this end, we extend BGG's (1999) model by considering credit contracts between the delegates of households and borrowing FIs, in addition to credit contracts between the FIs and borrowing entrepreneurs. Here, financial intermediation takes place through two types of credit contracts that are chained. Similar to BGG (1999), credit-constrained entrepreneurs finance their investment projects with their own net worth and borrowings from the FIs through the first type of credit contracts. In contrast to BGG (1999), the FIs are also credit constrained in our model. Thus, FIs finance their loans to these entrepreneurs with their own net worth and borrowings through the second type of credit contracts. Informational friction exists in both types of credit contracts, and the two borrowing rates are contingent on both the entities' net worth. Consequently, the size of the investment is influenced by the net worth of the two entities.

To commence the analysis, we use the static framework to demonstrate how the respective net worth of FIs and entrepreneurs influences external finance premium, which is determined by credit contracts. Since the two credit contracts are chained, the two entities' net worth works complementarily. For instance, when either of the two contracts is severely affected by the scarcity of either of the entities' net worth, the expected 
default probability of borrowers in the corresponding contract rises, pushing up the total cost of external finance disproportionately and squeezing the supply of funds to entrepreneurs. Because of the complementarity, there exists a distribution of net worth across FIs and entrepreneurs that achieves the lowest external finance premium. The distribution has an implication for the aggregate economy because when other things are equal, a lower external finance premium fosters aggregate investment. We show that the current distribution of net worth in the U.S. is close to but not at the point where the lowest external finance premium and the largest investment are attained. The FIs' net worth is currently too low relative to entrepreneurial net worth.

Next, we illustrate the model's dynamic properties by simulating the model calibrated to the U.S. economy in the following three ways. First, we investigate how the FIs' credit friction influences the financial accelerator effect through the development of their net worth. To this end, we develop a hypothetical model that abstracts from the FIs' credit friction à la BGG (1999), and compare its economic implications with those of our model. We find that our model propagates and amplifies shocks to the economy greater than the BGG model does, thanks to the endogenous development of the two entities' net worth. Since the two entities' net worth works complementarily, the financial accelerator effect is reinforced by the presence of FIs' net worth, together with entrepreneurial net worth.

Second, we investigate the relative significance of FIs' and non-entrepreneurial net worth in aggregate fluctuations. The model reveals that a net-worth shock to FIs is more pronounced and leads to greater aggregate consequences than the same size of networth shock to non-financial entrepreneurs. This is attributed to the fact that in the U.S. economy, the net-worth distribution between the two borrowing sectors is biased: entrepreneurs own a larger portion of the total net worth relative to FIs. Because the net worth of the two entities works complementarily, a variation of FIs' net worth brings about a disproportionately large impact on aggregate investment, as compared to a variation of the same size in entrepreneurial net worth.

Third, we investigate the implications of net-worth distribution across FIs and nonfinancial sectors for aggregate economic fluctuations. To this end, we develop another hypothetical economy where the net worth is distributed equally across the two sectors in the steady state. We show that the aggregate consequences of exogenous shocks in the economy substantially differ from the model calibrated to the actual net-worth distribution in the U.S. economy. The net worth distribution is, therefore, important to the magnitude of the financial accelerator effect.

Our model is constructed with reference to a large volume of literature that attempts to outline the role of the financial market in the economy. Within this, our model is particularly close to three strands of literature. The first strand extends BGG's (1999) model from quantitative aspects. This includes Christiano, Motto, and Rostagno (2004, 2013, hereafter CMR), and Christiano, Eichenbaum, and Trabandt (2013), and involves the estimation of the model. The key difference of our model from these works is the inclusion of another financial accelerator, the FIs' net worth, into otherwise the same 
model by BGG (1999). ${ }^{1,2}$ The second strand of literature, which has accumulated since the financial crisis, explores the theoretical basis for unconventional monetary policy during the current financial crisis and quantifies the role of FIs' net worth in the economy. This includes Gerali, et al. (2010), Gertler and Kiyotaki (2010), and Gertler and Karadi (2011). Our work differs from these works in that it incorporates the net worth of non-financial entrepreneurs as well as that of FIs. Consequently, our model is able to highlight the distinct role played by the net worth of each of the two entities, as well as that played by the net-worth distribution across FIs and non-financial sectors in macroeconomic dynamics. The third strand includes works that incorporate the net worth of both FIs and firms, based on the moral hazard model of Holmstrom and Tirole (1997). These works include Chen (2001), Aikman and Paustian (2006), and Meh and Moran (2010). ${ }^{3}$ Again, our work differs from these studies in showing that the net-worth distribution between FIs and entrepreneurs has a substantial role in economic dynamics. In these models, only the sum of the two types of net worth is relevant in determining aggregate investment and net-worth distribution across sectors is not given a specific role.

The current model has a policy implication regarding the intensified Basel bank regulations that have come into effect after the financial crisis. The ongoing bank regulatory framework gives the FIs' net worth a pivotal role in achieving financial stability. The regulation, however, comes at a cost, and studies such as Van den Heuvel (2008), Kato, et al. (2011), and Miles, et al. (2013) use the DSGE framework to evaluate the overall benefits and costs associated with the regulation. Though our model does not explicitly address the capital requirement confronting FIs, our results suggest that the regulatory framework that protects banks' net worth from irrational exuberance or fosters its accumulation may be beneficial for macroeconomic stability. It is also notable that our model shows that there may be a point where a marginal increase in banks' net worth delivers undesirable outcomes.

The rest of the paper is organized as follows. Section 2 presents our financial accelerator model, where both FIs and entrepreneurs are credit constrained. Section 3

\footnotetext{
${ }^{1}$ The only exceptions are works by Markovic (2006) and Zhang (2009). They incorporate the banking sector into the BGG model, where banks finance their activities by issuing equities and collecting deposits from households in each period. In contrast to our model, however, there is no informational friction in the credit contracts between banks and households. Furthermore, banks' borrowing rates are determined by households' optimization problem, and not by the banks' net worth. Consequently, the endogenous development of banks' net worth does not act as a financial accelerator.

${ }^{2}$ Brzoza-Brzezina, et al. (2013) discuss two standard ways of incorporating financial friction into DSGE models. The first class of models is based on collateral constraints à la Kiyotaki and Moore (1997); the second is based on Carlstrom and Fuerst (1997) and BGG (1999), and focuses on the role of external finance premiums. Our contribution is to have extended the second class of models by shedding light on the role played by FIs' net worth. For other directions of modeling financial sectors, see Goodfriend and McCallum (2007), which sheds light on the monetary aggregate in banking activity.

${ }^{3}$ See also Zeng (2011), which analyzes the role of the net worth of banks and firms in a static framework.
} 
demonstrates quantitative implications for our economy, based on the model calibrated to the United States. In Section 4, we conclude the analysis.

\section{The Model Economy}

This section describes our model. The economy consists of a credit market and goods markets, and seven types of agents: a household, investors, FIs, entrepreneurs, capital goods producers, final goods producers and a government.

In the credit market, the FIs and the entrepreneurs as well as the investors make credit contracts that are subject to credit frictions. ${ }^{4}$ The entrepreneurs are the ultimate borrowers of funds in the economy. They own net worth, but not enough amount to finance their projects. They thus engage in credit contracts with the FIs to raise the funds (hereafter FE contracts). The FIs also own net worth but not enough amount to finance their loans to the entrepreneurs. Therefore, they engage in credit contracts with the investors in order to borrow the rest of the funds needed for the loans (hereafter IF contracts). The investors collect deposits from the household, the ultimate lender of the funds, in a competitive market, and invest what they collect as loans to the FIs. ${ }^{5}$ The two credit contracts are chained so that the entrepreneurs cannot finance their projects if either of the credit contracts does not hold. The FIs are monopolistic loan suppliers to the entrepreneurs. ${ }^{6}$ There is a continuum of the FIs and the entrepreneurs, indexed by type $i$ and group $j_{i}$, respectively, and an entrepreneur of group $j_{i}$ borrows only from the FI of type $i .^{7}$ Ensuring the participation constraints of the entrepreneurs as well as the investors, the FIs determine the borrowing rates of the above two credit contracts.

Our goods markets consist of input markets and output markets for final goods, and capital goods markets. These markets are competitive, and prices of all goods are flexible. Final goods producers possess Cobb-Douglas production technology that converts capital and labor input into final goods. Entrepreneurs purchase capital goods from capital goods producers using the funds they borrowed in the credit market and lend the capital goods to final goods producers. Labor inputs are supplied by the household, FIs, and entrepreneurs. Once produced, final goods are allocated to consumption and investment in the competitive final goods market.

\footnotetext{
${ }^{4}$ Our setting regarding credit market is built upon BGG (1999). Figures 1 and 2 illustrate how our chained credit contracts model departs from their model.

${ }^{5}$ The investors are interpreted as the financial institutions such as pension or mutual funds that act as the fund suppliers to the FIs in the credit market.

${ }^{6}$ The FIs in our model are broadly defined as agents that intermediate funds from ultimate lenders, the households, to ultimate borrowers, the entrepreneurs. In this sense, our FIs includes a shadow banking system discussed in Allen (2001), Gorton and Winton (2003), and Gorton (2008).

${ }^{7}$ See also Klein (1971), Monti (1972), and Freixas and Rochet (2008) for modeling of monopolistic banks.
} 


\subsection{Credit Market}

\subsubsection{FE contract}

\section{Basic setting}

The FE contract is made between an FI and a continuum of the entrepreneurs. In period $t$, each type $i$ FI offers a loan contract to an infinite number of group $j_{i}$ entrepreneurs. ${ }^{8}$ An entrepreneur in group $j_{i}$ owns net worth $N_{E, j_{i}}\left(s^{t}\right)$ and purchases capital of $Q\left(s^{t}\right) K_{j_{i}}\left(s^{t}\right)$, where $s^{t}$ is the whole history of states until period $t, Q\left(s^{t}\right)$ is the price paid per unit of capital, and $K_{j_{i}}\left(s^{t}\right)$ is the quantity of capital purchased by the group $j_{i}$ entrepreneur. Since the net worth $N_{E, j_{i}}\left(s^{t}\right)$ of the entrepreneurs is smaller than the amount of the capital purchase $Q\left(s^{t}\right) K_{j_{i}}\left(s^{t}\right)$, the entrepreneur raises the rest of the funds $Q\left(s^{t}\right) K_{j_{i}}\left(s^{t}\right)-N_{E, j_{i}}\left(s^{t}\right)$ from the type $i$ FI. The net return to a capital of a group $j_{i}$ entrepreneur is a product of the two elements: an aggregate return to capital $R_{E}\left(s^{t+1}\right)$ and an idiosyncratic productivity shock $\omega_{E, j_{i}}\left(s^{t+1}\right)$, which we call the entrepreneurs' riskiness hereafter, that is specific to the group $j_{i}$ entrepreneur. ${ }^{9}$ There is informational asymmetry between lenders and borrowers in the FE contract and the FI cannot observe the realization of the idiosyncratic shock $\omega_{E, j_{i}}\left(s^{t+1}\right)$ without paying the monitoring cost $\mu_{E}$. Under this credit friction, the FE contract specifies:

- the amount of debt that the group $j_{i}$ entrepreneur borrows from a type $i \mathrm{FI}$, $Q\left(s^{t}\right) K_{j_{i}}\left(s^{t}\right)-N_{E, j_{i}}\left(s^{t}\right)$, and

- a cut-off value of idiosyncratic productivity shock $\omega_{E, j_{i}}\left(s^{t+1}\right)$, which we denote by $\bar{\omega}_{E, j_{i}}\left(s^{t}\right)$, such that the group $j_{i}$ entrepreneur repays its debt if $\omega_{E, j_{i}}\left(s^{t+1}\right) \geq$ $\bar{\omega}_{E, j_{i}}\left(s^{t}\right)$ and declares the default if $\omega_{E, j_{i}}\left(s^{t+1}\right)<\bar{\omega}_{E, j_{i}}\left(s^{t}\right)$.

\section{Entrepreneurs' participation constraint}

Based on the FE contract, a portion $\int_{\bar{\omega}_{E, j_{i}}\left(s^{t+1} \mid s^{t}\right)}^{\infty} d F_{E}\left(\omega_{E}\right)$ of the entrepreneurs do not default and the rest of them defaults. Ex post, a non-default entrepreneur $j_{i}$ receives the following net return to its capital holdings

$$
\left(\omega_{E, j_{i}}\left(s^{t+1}\right)-\bar{\omega}_{E, j_{i}}\left(s^{t}\right)\right) R_{E}\left(s^{t+1} \mid s^{t}\right) Q\left(s^{t}\right) K_{j_{i}}\left(s^{t}\right) .
$$

The entrepreneurial loan rate $Z_{E, j_{i}}\left(s^{t+1} \mid s^{t}\right)$ is therefore given by

${ }^{8}$ We assume that the bankruptcy cost associated with a direct credit contract between the investors and the enptrepreneurs is high enough so that there is no rational such contracts are made. By the similar assumption, a contract made between a type $i$ FI and group $j_{i^{*}}$ entrepreneurs for $i \neq i^{*}$ are left out from our analysis.

${ }^{9}$ Here, $\omega_{E, j_{i}}\left(s^{t}\right)$ is a unit mean, lognormal random variable distributed independently over time and across entrepreneurs. We express its density function by $f_{E}\left(\omega_{E, j_{i}}\right)$, and its cumulative distribution function by $F_{E}\left(\omega_{E, j_{i}}\right)$. 


$$
Z_{E, j_{i}}\left(s^{t+1} \mid s^{t}\right) \equiv \frac{\bar{\omega}_{E, j_{i}}\left(s^{t}\right) R_{E}\left(s^{t+1} \mid s^{t}\right) Q\left(s^{t}\right) K_{j_{i}}\left(s^{t}\right)}{Q\left(s^{t}\right) K_{j_{i}}\left(s^{t}\right)-N_{E, j_{i}}\left(s^{t}\right)} .
$$

A group $j_{i}$ entrepreneur joins the FE contract only when the return from the credit contract is at least equal to the opportunity cost. Instead of participating in the credit contract, a group $j_{i}$ entrepreneur can purchase capital goods using only its own net worth $N_{E, j_{i}}\left(s^{t}\right)$. In this case, Ex ante, the entrepreneur expects to receive the earning $R_{E}\left(s^{t+1} \mid s^{t}\right) N_{E, j_{i}}\left(s^{t}\right)$, and ex post it receives the earning $\omega_{E, j_{i}}\left(s^{t+1}\right) R_{E}\left(s^{t+1}\right) N_{E, j_{i}}\left(s^{t}\right)$. Therefore, an FE contract between an FI and group $j_{i}$ entrepreneurs is agreed by the entrepreneurs only when the following inequality is expected to hold:

$$
\begin{gathered}
\left(\int_{\bar{\omega}_{E, j_{i}}\left(s^{t+1} \mid s^{t}\right)}^{\infty}\left(\omega_{E}-\bar{\omega}_{E, j_{i}}\left(s^{t}\right)\right) d F_{E}\left(\omega_{E}\right)\right) R_{E}\left(s^{t+1} \mid s^{t}\right) Q\left(s^{t}\right) K_{j i}\left(s^{t}\right) \\
\geq R_{E}\left(s^{t+1} \mid s^{t}\right) N_{E, j_{i}}\left(s^{t}\right) \text { for } \forall j_{i}, s^{t+1} .
\end{gathered}
$$

From the perspective of a group $j_{i}$ entrepreneur, the left-hand side of inequality (2) is the expected return from the FE contract, and the right-hand side of inequality (2) is the expected return from investing the entrepreneurial current net worth $N_{E, j_{i}}\left(s^{t}\right)$ without making credit contracts. In the analysis below, we focus on the equilibrium where equation (2) holds with equality in all realizations of states.

\section{FIs' profit from the FE contract}

The expected earnings of the type $i$ FI from an FE contract is obtained:

$$
\Phi_{E}\left(\bar{\omega}_{E, j_{i}}\left(s^{t}\right)\right) R_{E}\left(s^{t+1} \mid s^{t}\right) Q\left(s^{t}\right) K_{j_{i}}\left(s^{t}\right),
$$

where

$$
\Phi_{E}\left(\bar{\omega}_{E, j_{i}}\left(s^{t}\right)\right) \equiv\left(\int_{\bar{\omega}_{E, j_{i}}\left(s^{t}\right)}^{\infty} \bar{\omega}_{E, j_{i}}\left(s^{t}\right) d F_{E}\left(\omega_{E}\right)\right)-\left(\mu_{E} \int_{0}^{\bar{\omega}_{E, j_{i}}\left(s^{t}\right)} \omega_{E} d F_{E}\left(\omega_{E}\right)\right) .
$$

Note that $\mu_{E} \omega_{E, j_{i}}\left(s^{t+1}\right) R_{E}\left(s^{t+1}\right) Q\left(s^{t}\right) K_{j_{i}}\left(s^{t}\right)$ is the ex post monitoring cost that a type $i$ FI pays when a group $j_{i}$ entrepreneur declares the default. Since a type $i$ FI makes contracts with a continuum number of group $j_{i}$ entrepreneurs, its expected total monitoring cost is given by the second term of $\Phi_{E}\left(\bar{\omega}_{E, j_{i}}\left(s^{t}\right)\right)$ multiplied by $R_{E}\left(s^{t+1} \mid s^{t}\right) Q\left(s^{t}\right) K_{j_{i}}\left(s^{t}\right)$.

For the convenience of analysis below, we define the expected return on the loans from a type $i$ FI to the group $j_{i}$ entrepreneurs, $R_{F}\left(s^{t+1} \mid s^{t}\right)$, as

$$
\int_{j_{i}} \Phi_{E}\left(\bar{\omega}_{E, j_{i}}\left(s^{t}\right)\right) R_{E}\left(s^{t+1} \mid s^{t}\right) Q\left(s^{t}\right) K_{j_{i}}\left(s^{t}\right) d j_{i}
$$




$$
\equiv R_{F}\left(s^{t+1} \mid s^{t}\right)\left(Q\left(s^{t}\right) K_{i}\left(s^{t}\right)-N_{E, i}\left(s^{t}\right)\right) \text { for } \forall s^{t+1} \mid s^{t},
$$

where

$$
K_{i}\left(s^{t}\right) \equiv \int_{j_{i}} K_{j_{i}}\left(s^{t}\right) d j_{i}, N_{E, i}\left(s^{t}\right) \equiv \int_{j_{i}} N_{E, j_{i}}\left(s^{t}\right) d j_{i} .
$$

The left-hand side of equation (4) represents the profit that a type $i$ FI receives from a continuum number of the FE contracts with group $j_{i}$ entrepreneurs, and $Q\left(s^{t}\right) K_{i}\left(s^{t}\right)-$ $N_{E, i}\left(s^{t}\right)$ represents the total amount of loans lent to the group $j_{i}$ entrepreneurs.

\subsubsection{IF contract}

\section{Basic setting}

The IF contract is made between an investor and a continuum of the FIs. In period $t$, each type $i$ FI holds the net worth $N_{F, i}\left(s^{t}\right)$ and makes loans to group $j_{i}$ entrepreneurs at an amount of $Q\left(s^{t}\right) K_{i}\left(s^{t}\right)-N_{E, i}\left(s^{t}\right)$. Since the FI's net worth is smaller than its loans to the entrepreneurs, it borrows the rest $Q\left(s^{t}\right) K_{i}\left(s^{t}\right)-N_{F, i}\left(s^{t}\right)-N_{E, i}\left(s^{t}\right)$ from the investor. Each type $i$ FI faces an idiosyncratic productivity shock $\omega_{F, i}\left(s^{t+1}\right)$, which we call the FIs' riskiness. This shock $\omega_{F, i}\left(s^{t+1}\right)$ represents the technological differences across the FIs, for example, those associated with risk management, the maturity mismatch control, and loan securitization. ${ }^{10}$ Consequently, the FI's receipt from the loans to the entrepreneurs is given by $\omega_{F, i}\left(s^{t+1}\right) R_{F}\left(s^{t+1}\right)\left(Q\left(s^{t}\right) K_{i}\left(s^{t}\right)-N_{E, i}\left(s^{t}\right)\right) .{ }^{11}$ Similarly to the FE contract, there is informational asymmetry between the lender and the borrowers in the IF contract and the investor can observe the realization of the shock only by paying the monitoring $\operatorname{cost} \mu_{F}$. Under this credit friction, the IF contract specifies: ${ }^{12}$

- the amount of debt that a type $i$ FI borrows from the investor, $Q\left(s^{t}\right) K_{i}\left(s^{t}\right)-$ $N_{E, i}\left(s^{t}\right)-N_{F, i}\left(s^{t}\right)$, and

\footnotetext{
${ }^{10}$ Alternatively, one may interpret $\omega_{F, i}\left(s^{t}\right)$ as an idiosyncratic productivity shock that is specific to a group of firms, such as those in the same industry $i$ or those located in the same region $i$, and interpret $\omega_{E, j_{i}}\left(s^{t}\right)$ as firm specific shock for those belonging to the same industry or region $i$. Suppose that there is an infinite number of industries (regions) that consist of an infinite number of firms and each type $i$ FI lends funds to only one of the industries (regions) $i$. Industry-specific (region-specific) shock then affects the type $i$ FI's earnings exclusively as if the FI is hit by an idiosyncractic productivity shock that is specific to type $i$ FI.

${ }^{11}$ Similarly to the entrepreneurial riskiness $\omega_{E, j_{i}}$, the FIs' riskiness $\omega_{F, i}$ is a unit mean, lognormal random variable distributed independently over time and across FIs $i$. Its density function and its cumulative distribution function are given by $f_{F}\left(\omega_{F, i}\right)$ and $F_{F}\left(\omega_{F, i}\right)$, respectively.

${ }^{12}$ Similarly to BGG (1999), the contents of the FI contracts, the cut-off value $\bar{\omega}_{F, j_{i}}\left(s^{t+1} \mid s^{t}\right)$ is contingent on aggregate states. By contrast, because of the structure of the equation (2), the cut-off value $\bar{\omega}_{E, j_{i}}\left(s^{t}\right)$ is not contingent on aggregate states.
} 
- a cut-off value of idiosyncratic shock $\omega_{F, i}\left(s^{t+1}\right)$, which we denote by $\bar{\omega}_{F, i}\left(s^{t+1} \mid s^{t}\right)$, such that the FI repays debt if $\omega_{F, i}\left(s^{t+1}\right) \geq \bar{\omega}_{F, i}\left(s^{t+1} \mid s^{t}\right)$ and declare the default if $\omega_{F, i}\left(s^{t+1}\right)<\bar{\omega}_{F, i}\left(s^{t+1} \mid s^{t}\right)$.

\section{FIs' profit from the two credit contracts}

According to the IF contract, a portion $\int_{\bar{\omega}_{F, i}\left(s^{t+1} \mid s^{t}\right)}^{\infty} d F_{F}\left(\omega_{F}\right)$ of the FIs do not default while the rest of them defaults. The net profit of a non-default FI $i$ equals its receipt from the FE contract multiplied by the idiosyncratic shock $\omega_{F, i}\left(s^{t+1}\right)$ minus repayment to the investor:

$$
\left(\omega_{F, i}\left(s^{t+1}\right)-\bar{\omega}_{F, i}\left(s^{t+1} \mid s^{t}\right)\right) R_{F}\left(s^{t+1} \mid s^{t}\right)\left(Q\left(s^{t}\right) K_{i}\left(s^{t}\right)-N_{E, i}\left(s^{t}\right)\right) .
$$

The FIs' loan rate $Z_{F, i}\left(s^{t+1} \mid s^{t}\right)$ is therefore given by

$$
Z_{F}\left(s^{t+1} \mid s^{t}\right) \equiv \frac{\bar{\omega}_{F, i}\left(s^{t+1} \mid s^{t}\right) R_{F}\left(s^{t+1} \mid s^{t}\right)\left(Q\left(s^{t}\right) K_{i}\left(s^{t}\right)-N_{E, i}\left(s^{t}\right)\right)}{Q\left(s^{t}\right) K_{i}\left(s^{t}\right)-N_{F, i}\left(s^{t}\right)-N_{E, i}\left(s^{t}\right)} .
$$

\section{Investors' participation constraint}

There is a participation constraint for the investor in the IF contract. Given the risk-free rate of return in the economy $R\left(s^{t}\right)$, the investor's profit from the investment in the loans to the FIs must at least equal the opportunity cost of lending. That is

$$
\begin{aligned}
& \Phi\left(\bar{\omega}_{F, i}\left(s^{t+1} \mid s^{t}\right)\right) R_{F}\left(s^{t+1} \mid s^{t}\right)\left(Q\left(s^{t}\right) K_{i}\left(s^{t}\right)-N_{E, i}\left(s^{t}\right)\right) \\
\geq & R\left(s^{t}\right)\left(Q\left(s^{t}\right) K_{i}\left(s^{t}\right)-N_{F, i}\left(s^{t}\right)-N_{E, i}\left(s^{t}\right)\right) \text { for } \forall i, s^{t+1},
\end{aligned}
$$

where

$$
\Phi_{F}\left(\bar{\omega}_{F, i}\left(s^{t+1} \mid s^{t}\right)\right) \equiv \bar{\omega}_{F, i}\left(s^{t+1} \mid s^{t}\right) \int_{\bar{\omega}_{F, i}\left(s^{t+1} \mid s^{t}\right)}^{\infty} d F_{F}\left(\omega_{F}\right)-\mu_{F} \int_{0}^{\bar{\omega}_{F, i}\left(s^{t+1} \mid s^{t}\right)} \omega_{F} d F_{F}\left(\omega_{F}\right) .
$$

We assume that investors face perfect competition. Because the IF contract is contingent on aggregate states, the participation constraint (6) holds with equality state by state.

\subsubsection{Optimal credit contract}

Given the structure of the FE contract and the IF contract, a type $i$ FI optimally chooses $K_{j_{i}}\left(s^{t}\right), \bar{\omega}_{E, j_{i}}\left(s^{t+1} \mid s^{t}\right), K_{i}\left(s^{t}\right)$, and $\bar{\omega}_{F, i}\left(s^{t+1} \mid s^{t}\right)$. The expected profit of a type $i$ FI is given by 
$\sum_{s^{t+1}} \Pi\left(s^{t+1} \mid s^{t}\right)\left(\int_{\bar{\omega}_{F, i}\left(s^{t+1} \mid s^{t}\right)}^{\infty}\left(\omega_{F, i}-\bar{\omega}_{F, i}\left(s^{t+1} \mid s^{t}\right)\right) d F_{F}\left(\omega_{F}\right)\right) R_{F}\left(s^{t+1} \mid s^{t}\right)\left(Q\left(s^{t}\right) K_{i}\left(s^{t}\right)-N_{E, i}\left(s^{t}\right)\right)$,

where $\Pi\left(s^{t+1} \mid s^{t}\right)$ is the probability weight for state $s^{t+1}$, depending on the information set available at period $t$. The FI maximizes the term (8), subject to the investor's participation constraint (6) and entrepreneurial participation constraint (2). The first-order conditions are given in Appendix A.

The first-order condition and the two participation constraints, equation (2) and (6), characterize the contents of the two credit contracts. Arranging equations (4) and (6) delivers the relationship between the two net worths $N_{F}\left(s^{t}\right)$ and $N_{E}\left(s^{t}\right)$ and the external finance premium $\mathrm{E}_{t}\left\{R_{E}\left(s^{t+1}\right)\right\} R\left(s^{t}\right)^{-1}$, the cost-of-funds curve, that is the key equation in our model:

$$
\begin{aligned}
\frac{\mathrm{E}_{t}\left\{R_{E}\left(s^{t+1}\right)\right\}}{R\left(s^{t}\right)}= & \overbrace{\left(1-\frac{N_{F}\left(s^{t}\right)}{Q\left(s^{t}\right) K\left(s^{t}\right)}-\frac{N_{E}\left(s^{t}\right)}{Q\left(s^{t}\right) K\left(s^{t}\right)}\right)}^{[1]} \\
& \times \overbrace{\Phi_{F}\left(\bar{\omega}_{F}\left(\frac{N_{F}\left(s^{t}\right)}{Q\left(s^{t}\right) K\left(s^{t}\right)}, \frac{N_{E}\left(s^{t}\right)}{Q\left(s^{t}\right) K\left(s^{t}\right)}\right)\right)^{-1}}^{\text {ratio of the debt to the size of the capital investment }}
\end{aligned}
$$

[3] inverse of share of profit going to the FIs in the FE contract

$$
\begin{aligned}
\times \quad \overbrace{\Phi_{E}\left(\bar{\omega}_{E}\left(\frac{N_{E}\left(s^{t}\right)}{Q\left(s^{t}\right) K\left(s^{t}\right)}\right)\right)^{-1}} \\
\equiv S\left(n_{F}\left(s^{t}\right), n_{E}\left(s^{t}\right)\right) .
\end{aligned}
$$

Here, $n_{F}\left(s^{t}\right)$ and $n_{E}\left(s^{t}\right)$ represent the ratio of the FIs' net worth and entrepreneurial net worth to the total amount of capital investment, respectively. ${ }^{13}$

Since $R_{E}\left(s^{t+1}\right)$ equals the aggregate return to capital in the equilibrium, for given size of risk-free rate, a higher external finance premium implies that capital investment is more depressed. This premium is influenced by two entities' net worth to capital ratios through the three terms in equation (9): [1] the ratio of total debt to aggregate capital; [2] the share of profit in the IF contract going to the investors; and [3] the share of profit in the FE contract going to the FIs.

The term [1] represents the capital investment leverage from the investor's viewpoint. Since the two credit contracts are chained, a decline in either one of the two entities'

\footnotetext{
${ }^{13}$ Notice that because the ratio of net worth to capital $n_{F}\left(s^{t}\right)$ and $n_{E}\left(s^{t}\right)$ are identical across types of the FIs and across the groups of entrepreneurs, subscripts $i$ and $j_{i}$ are both dropped from the expressions. Consequently, similarly to BGG (1999), the developments of these ratios for individual FI and the entrepreneur are tracked by the ratio of aggregate net worth to aggregate capital.
} 
net worth indicates a higher leverage to the investor. In compensation for the expected default increase, therefore, the investor requires a higher return from the investment regardless of the holder of the net worth. The terms [2] and [3] show how each of the net worth affects the external finance premium. When the two entities' net worth deteriorates, the default probability increases, dropping the lenders' shares as indicated in equations (3) and (7) due to the increases in the default costs. Other things being equal, a reduction in the lenders' share needs to be met with an increase in the external finance premium so that the investor's participation constraint is maintained.

It is notable that the term [2] is affected by both of the two net worth to capital ratios, $n_{F}\left(s^{t}\right)$ and $n_{E}\left(s^{t}\right)$, and that the term [3] is affected only by the entrepreneurial net worth to capital ratio $n_{E}\left(s^{t}\right)$. Accordingly, marginal changes in the two entities' net worth bring about a different size of impact on the external finance premium. Consequently, the distribution of the net worth across the FIs and the entrepreneurs has a significant implication for the investment and aggregate economy. To see this more in detail, in the following section, we numerically investigate the property of $S\left(n_{F}\left(s^{t}\right), n_{E}\left(s^{t}\right)\right) .{ }^{14}$

\subsubsection{Cost-of-Funds Curve}

\section{Role of the FIs' net worth and the entrepreneurial net worth}

We numerically evaluate the cost-of-funds curve (9), a relationship between the external finance premium and the net worth to capital ratio in each of the borrowing sectors. ${ }^{15}$ We show how the external finance premium and the expected default costs vary with a size of one entity's net worth, keeping one other's net worth unchanged. As shown in the second term of the equations (3) and (7), the expected default costs are the key determinants of the lenders shares in equation (9), affecting the external finance premium.

Figure 3 indicates that the external finance premium is decreasing in both of the FIs' net worth to capital ratio (left panel) and the entrepreneurial net worth to capital ratio (right panel). As shown in Figure 4, when a size of capital investment becomes large relative to entities' net worth, which implies a smaller net worth to capital ratio, the expected default cost of the corresponding credit contract elevates, leading to a higher external finance premium through the term [2] or the term [3] in equation (9). In addition, since a shortage of the two entities' net worth implies a higher investment leverage for the investors, the term [1] also helps increase the external finance premium.

\footnotetext{
${ }^{14}$ Luk and Vines (2010) prove analytically that $S(\cdot)$ is decreasing with both $n_{F}\left(s^{t}\right)$ and $n_{E}\left(s^{t}\right)$.

${ }^{15}$ In this section, unless otherwise noted, we set the model parameters pertaining to the two credit contracts following BGG (1999). Namely, we set the values for parameters $\mu_{E}, \sigma_{E}$, and $1-\gamma_{E}$ equal to the values of the monitoring cost, the entrepreneurial riskiness and the entrepreneurial death rate reported in BGG (1999), respectively. We further assume that $\mu_{F}=\mu_{E}, \sigma_{F}=\sigma_{E}$, and $\gamma_{F}=\gamma_{E}$ so that the two credit contracts are symmetric in terms of these parameters.
} 
The roles of the two net worths in determining the external finance premium are quantitatively different. This is because a change in the FIs' net worth to capital ratio has no influence on the expected default cost of the FE contract, while a change in the entrepreneurial net worth to capital affects the expected default cost of both contracts, as shown in Figure 4. Because the entrepreneur's participation constraint is independent of the FI's net worth while the investor's participation constraint is affected by the entrepreneurial net worth, their impacts on the default probability becomes asymmetric. Consequently, other things being equal, an increase in the entrepreneur's net worth reduces the external finance premium more than does the FIs' net worth. ${ }^{16}$

\section{Role of the distribution of net worth across sectors}

We next discuss the implication of the distribution of net worth for the external finance premium. In contrast to BGG (1999) in which only the entrepreneurial net worth is studied, our model consists of the two distinct net worths distributed to the FIs and the entrepreneurs. Since the two net worths are not substitutable across sectors and affect the contents of the two credit contracts differently, the relative size of each net worth is important for the external finance premium.

To see this distributional aspect of the model in detail, we display how the FIs' share in the net worth alters the external finance premium in Figure 5. The share of the net worth held by the FI sector is depicted on the horizontal axis and the corresponding external finance premium is depicted on the vertical axis. We set the ratio of total net worth to the total amount of capital investment equal to 0.6. We first concentrate our analysis on the case where the technology parameters of the two credit contracts, the monitoring costs and riskiness, are identical, namely, $\mu_{F}=\mu_{E}$ and $\sigma_{F}=\sigma_{E}$. The result under this symmetric assumption is reported by the solid lines in each figure.

The U-shaped cost-of-funds curve in Figure 4 indicates that a net-worth disruption in a sector with a lower net worth causes a disproportionately large increase in the external finance premium. In other word, a large discrepancy between the size of FIs' net worth and that of the entrepreneurial net worth aggravates the condition of external finance, which dampens aggregate investment. By contrast, when the two entities' net worth is distributed more evenly, the external finance premium is maintained at a low level, encouraging the investment. ${ }^{17}$ Under our chained credit contracts, the two net worths work complementarily in reducing the external finance premium. This complementarity makes a sharp contrast with the models based on Aikman and Paustian (2006) and Meh and Moran (2010), where the distribution of the net worth plays no role in determining

\footnotetext{
${ }^{16}$ As we demonstrate below, however, our calibration based on the U.S. economy suggests that the size of net worth and the technologies associated with the credit contracts are asymmetric across the two borrowing sectors. Consequently, despite the argument here, the FIs' net worth plays a disproportionately large effect on the external finance premium.

${ }^{17}$ The external finance premium is the lowest at the point where the FIs' share reaches around $40 \%$, reflecting the asymmetric role of the two net worths in the credit contracts discussed above (see also Figure 4).
} 
the external finance premium in the economy.

Figure 6 illustrates the same points from the viewpoints of the expected default costs. When the FIs' net worth is relatively scarce, for instance $N_{F} /\left(N_{F}+N_{E}\right)=0.2$, a unit transfer of the net worth from the entrepreneurs to the FIs lowers the expected default cost of the IF contract significantly, raising that of the FE contract only moderately. Similarly, when the entrepreneurial net worth is relatively scarce, for instance, $N_{F} /\left(N_{F}+N_{E}\right)=0.8$, the same transfer lowers the expected default cost of the IF contract only moderately, raising that of the FE contract significantly. Because of these non-linearities, the external finance premium becomes highly sensitive to a change in net worth in a sector that possesses a relatively scarce net worth.

These properties are affected by the technology parameters associated with the two credit contracts. In Figures 5 and 6, the lines with black circles and the dotted lines display the cost-of-funds curve and the expected default costs when the monitoring costs are set to $\mu_{F}=\mu_{E} / 2=\mu / 2$, and $\mu_{F} / 2=\mu_{E}=\mu / 2$, respectively. In the former economy, for example, because the FIs' default cost is less costly, a scarcity in the FIs' net worth leads to a limited rise in the external finance premium. Consequently, the cost-of-funds curve is shifted downwards and tilted to the left. A similar mechanism is at work in the latter economy.

In Figures 7 and 8, the lines with black circles and the dotted lines display the cost-offunds curve and the expected default costs when the riskiness is set to $\sigma_{F}=\sigma_{E} / 2=\sigma / 2$, and $\sigma_{F} / 2=\sigma_{E}=\sigma / 2$, respectively. Similarly to the consequence of reducing monitoring costs, the decrease in the riskiness lowers the default cost and shifts the cost-of-funds curve downwards. Because the credit friction stemming from the information asymmetry is moderated in the IF contract, the default cost of the FIs in the IF contract falls, shifting the bottom of the U-shape to the left.

\subsubsection{Dynamic Behavior of Net Worth}

The net worth of the FIs and the entrepreneurs, $N_{F}\left(s^{t}\right)$ and $N_{E}\left(s^{t}\right)$, depends on their earnings from the credit contracts and their labor income. Both FIs and entrepreneurs inelastically supply a unit of labor to final goods producers and receive labor income $W_{F}\left(s^{t}\right)$ and $W_{E}\left(s^{t}\right){ }^{18}$ The aggregate net worths of the FIs and the entrepreneurs are given by

$$
\begin{aligned}
& N_{F}\left(s^{t+1}\right)=\gamma_{F} V_{F}\left(s^{t}\right)+W_{F}\left(s^{t}\right)+\varepsilon_{N_{F}}\left(s^{t}\right), \\
& N_{E}\left(s^{t+1}\right)=\gamma_{E} V_{E}\left(s^{t}\right)+W_{E}\left(s^{t}\right)+\varepsilon_{N_{E}}\left(s^{t}\right),
\end{aligned}
$$

with

\footnotetext{
${ }^{18}$ See BGG (1999) and CMR (2008) for the technical reason behind this specification.
} 


$$
\begin{aligned}
V_{F}\left(s^{t}\right) & \equiv\left(\int_{\bar{\omega}_{F}\left(s^{t+1} \mid s^{t}\right)}^{\infty}\left(\omega_{F}-\bar{\omega}_{F}\left(s^{t+1} \mid s^{t}\right)\right) d F_{F}\left(\omega_{F}\right)\right) \Phi_{E}\left(\bar{\omega}_{E}\left(s^{t}\right)\right) R_{E}\left(s^{t+1}\right) Q\left(s^{t}\right) K\left(s^{t}\right), \\
V_{E}\left(s^{t}\right) & \equiv\left(\int_{\bar{\omega}_{E}\left(s^{t}\right)}^{\infty}\left(\omega_{E}-\bar{\omega}_{E}\left(s^{t}\right)\right) d F_{E}\left(\omega_{E}\right)\right) R_{E}\left(s^{t+1}\right) Q\left(s^{t}\right) K\left(s^{t}\right) .
\end{aligned}
$$

Here, $\gamma_{F}$ and $\gamma_{E}$ are probabilities that each FI and entrepreneur survives to the next period. The FIs and the entrepreneurs who are in business in period $t$ and fail to survive in period $t+1$ consume $\left(1-\gamma_{F}\right) V_{F}\left(s^{t}\right)$ and $\left(1-\gamma_{E}\right) V_{E}\left(s^{t}\right)$, respectively.

The net worth accumulations in both sectors are affected by exogenous shocks represented by $\varepsilon_{N_{F}}\left(s^{t}\right)$ and $\varepsilon_{N_{E}}\left(s^{t}\right)$ that are orthogonal to the fundamental earnings from the credit contracts. We assume these shocks are i.i.d. They are financial shocks that capture an "asset bubble," "irrational exuberance," or an "innovation in the efficiency of credit contracts," hitting the FI sector or the entrepreneurial sector. ${ }^{19}$

\subsection{The Rest of the Economy}

\section{Household}

A representative household is infinitely lived, and maximizes the following utility function:

$$
\max _{C\left(s^{t+l}\right), H\left(s^{t+l}\right), D\left(s^{t+l}\right)} \sum_{l=0}^{\infty} \beta^{t+l} \mathrm{E}_{t}\left\{\log C\left(s^{t+l}\right)-\chi \frac{H\left(s^{t+l}\right)^{1+\frac{1}{\eta}}}{1+\frac{1}{\eta}}\right\},
$$

subject to

$$
C\left(s^{t+l}\right)+D\left(s^{t+l}\right) \leq W\left(s^{t+l}\right) H\left(s^{t+l}\right)+R\left(s^{t+l-1}\right) D\left(s^{t+l-1}\right)+\Pi\left(s^{t+l}\right)-T\left(s^{t+l}\right),
$$

where $C\left(s^{t}\right)$ is final goods consumption, $H\left(s^{t}\right)$ is hours worked, $D\left(s^{t}\right)$ is real deposits held by investors, $W\left(s^{t}\right)$ is the real wage measured by the final goods, $R\left(s^{t-1}\right)$ is the real risk-free rate from the deposit $D\left(s^{t}\right)$ between time $t-1$ and $t$, and $T\left(s^{t}\right)$ is the lump-sum transfer. $\beta \in(0,1), \eta$ and $\chi$ are the subjective discount factor, the elasticity of leisure, and the utility weight on leisure. The first-order conditions associated with the household's maximization problem are given by

\footnotetext{
${ }^{19}$ The setting of these net worth shocks is borrowed from Gilchrist and Leahy (2002). See also CMR (2008) and Nolan and Thoenissen (2009) for the interpretation of these net worth shocks under credit market imperfection. In these studies, the exit ratio of entrepreneurs $\gamma_{E}$, that is analogous to $\gamma_{E}$ in the equation (11), obeys the stochastic law of motion, generating an unexpected change in the entrepreneurial net worth.
} 


$$
\begin{gathered}
\frac{1}{C\left(s^{t}\right)}=\beta \mathrm{E}_{t}\left\{\frac{1}{C\left(s^{t+1}\right)} R\left(s^{t+1}\right)\right\}, \\
W\left(s^{t}\right)=\chi H\left(s^{t}\right)^{\frac{1}{\eta}} C\left(s^{t}\right) .
\end{gathered}
$$

\section{Final Goods Producers}

Final goods producers are price takers in both input markets and output markets. They hire three types of labor inputs: $H\left(s^{t}\right), H_{F}\left(s^{t}\right)$, and $H_{E}\left(s^{t}\right)$, from the household, the FIs, and the entrepreneurs, and pay real wages $W\left(s^{t}\right), W_{F}\left(s^{t}\right)$, and $W_{E}\left(s^{t}\right)$ to each type of labor inputs, respectively. They rent capital $K\left(s^{t-1}\right)$ from the entrepreneurs with a rental price $R_{E}\left(s^{t}\right)$ in the beginning of each period and return it to the entrepreneurs at the end of each period. The maximization problem of the final goods producers is given by

$$
\begin{gathered}
\max _{Y\left(s^{t}\right), K\left(s^{t-1}\right), H\left(s^{t}\right), H_{F}\left(s^{t}\right), H_{E}\left(s^{t}\right)} Y\left(s^{t}\right)+Q\left(s^{t-1}\right) K\left(s^{t-1}\right)(1-\delta) \\
-R_{E}\left(s^{t}\right) Q\left(s^{t-1}\right) K\left(s^{t-1}\right)-W\left(s^{t}\right) H\left(s^{t}\right) \\
-W_{F}\left(s^{t}\right) H_{F}\left(s^{t}\right)-W_{E}\left(s^{t}\right) H_{E}\left(s^{t}\right),
\end{gathered}
$$

subject to

$$
\begin{aligned}
Y\left(s^{t}\right) & =A \exp \left(e^{A}\left(s^{t}\right)\right) K\left(s^{t-1}\right)^{\alpha} L\left(s^{t}\right)^{1-\alpha}, \\
L\left(s^{t}\right) & \equiv\left(H\left(s^{t}\right)\right)^{1-\Omega_{E}-\Omega_{F}}\left(H_{F}\left(s^{t}\right)\right)^{\Omega_{F}}\left(H_{E}\left(s^{t}\right)\right)^{\Omega_{E}},
\end{aligned}
$$

where $Y\left(s^{t}\right)$ is the final goods produced and $A \exp \left(e_{A}\left(s^{t}\right)\right)$ is the level of total factor productivity (TFP). $\delta \in(0,1], \alpha, \Omega_{E}$, and $\Omega_{F}$ are the depreciation rate of capital goods, the capital share, the share of the FIs' labor inputs, and the share of the entrepreneurial labor inputs. We assume that TFP evolves following the equation below:

$$
e_{A}\left(s^{t}\right)=\rho_{A} e_{A}\left(s^{t-1}\right)+\varepsilon_{A}\left(s^{t}\right)
$$

where $\rho_{A} \in(0,1)$ is the autoregressive root of the TFP and $\varepsilon_{A}\left(s^{t}\right)$ is the exogenous shock that is normally distributed with mean zero.

The first-order conditions of the final goods producers are

$$
\alpha \frac{Y\left(s^{t}\right)}{K\left(s^{t-1}\right)}-R_{E}\left(s^{t}\right) Q\left(s^{t-1}\right)+Q\left(s^{t-1}\right)(1-\delta)=0,
$$




$$
\begin{aligned}
(1-\alpha)\left(1-\Omega_{F}-\Omega_{E}\right) \frac{Y\left(s^{t}\right)}{H\left(s^{t}\right)} & =W\left(s^{t}\right), \\
(1-\alpha) \Omega_{F} \frac{Y\left(s^{t}\right)}{H_{F}\left(s^{t}\right)} & =W_{F}\left(s^{t}\right), \\
(1-\alpha) \Omega_{E} \frac{Y\left(s^{t}\right)}{H_{E}\left(s^{t}\right)} & =W_{E}\left(s^{t}\right) .
\end{aligned}
$$

\section{Capital Goods Producers}

Capital goods producers own technology that converts final goods to capital goods. They sell capital goods to the entrepreneurs in a competitive market with price $Q\left(s^{t}\right)$. In the beginning of the period $t$, the capital goods producers purchase $I\left(s^{t}\right)$ amount of final goods from final goods producers. They also receive $K\left(s^{t-1}\right)(1-\delta)$ of used capital goods from the entrepreneurs at price $Q\left(s^{t-1}\right)$. They then produce capital goods $K\left(s^{t}\right)$, using technology $F_{I}$. The capital goods producers' problem is to maximize the profit function given below:

$$
\begin{aligned}
\max _{I_{t}} & \sum_{l=0}^{\infty} \Pi\left(s^{t+l} \mid s^{t}\right) \Lambda_{t, t+l}\left(s^{t+l}\right) \\
\cdot & {\left[Q\left(s^{t+l}\right) K\left(s^{t+l}\right)-(1-\delta) Q\left(s^{t+l}\right) K\left(s^{t+l-1}\right)-I\left(s^{t+l}\right)\right], }
\end{aligned}
$$

where $\Lambda_{t, t+l}\left(s^{t+l}\right) \equiv \beta C\left(s^{t}\right) / C\left(s^{t+l}\right)$ is a discount factor and $F_{I}$ is defined as follows:

$$
F_{I}\left(I\left(s^{t+l}\right), I\left(s^{t+l-1}\right)\right) \equiv \frac{\kappa}{2}\left(\frac{I\left(s^{t+l}\right)}{I\left(s^{t+l-1}\right)}-1\right)^{2} .
$$

Note that $\kappa$ is a parameter that is associated with investment adjustment cost. $^{20}$

Because capital depreciates in each period, the evolvement of total capital available in period $t$ is given by

$$
K\left(s^{t}\right)=\left(1-F_{I}\left(I\left(s^{t}\right), I\left(s^{t-1}\right)\right)\right) I\left(s^{t}\right)+(1-\delta) K\left(s^{t-1}\right) .
$$

\section{Government}

The government collects a lump-sum tax from a household $T\left(s^{t}\right)$, and spends $G\left(s^{t}\right)$. A balanced budget is maintained in each period $t$ as:

\footnotetext{
${ }^{20} \mathrm{~A}$ term for used capital $K\left(s^{t-1}\right)$ sold by the entrepreneurs at the end of the period $t-1$ does not appear in equation (21). This is because, following BGG (1999), we assume that the price of capital that the entrepreneurs sell back to the capital goods producers, say $\bar{Q}\left(s^{t}\right)$, is close to the price of newly produced capital $Q\left(s^{t}\right)$ around the steady state.
} 


$$
G\left(s^{t}\right)=T\left(s^{t}\right)
$$

\section{Resource Constraint}

The resource constraint for final goods is written as

$$
\begin{aligned}
Y\left(s^{t}\right)= & C\left(s^{t}\right)+I\left(s^{t}\right)+G\left(s^{t}\right) \\
& +\mu_{F}\left(\int_{0}^{\bar{\omega}_{F}\left(s^{t+1} \mid s^{t}\right)} \omega_{F} d F_{F}\left(\omega_{F}\right)\right) R_{F}\left(s^{t}\right)\left\{Q\left(s^{t-1}\right) K\left(s^{t-1}\right)-N_{E}\left(s^{t-1}\right)\right\} . \\
& +\mu_{E}\left(\int_{0}^{\bar{\omega}_{E}\left(\mid s^{t}\right)} \omega_{E} d F_{E}\left(\omega_{E}\right)\right) R_{E}\left(s^{t}\right) Q\left(s^{t-1}\right) K\left(s^{t-1}\right) \\
& +\left(1-\gamma_{F}\right) V_{F}+\left(1-\gamma_{E}\right) V_{E} .
\end{aligned}
$$

The fourth and the fifth terms on the right-hand side of the equation represent the default costs spent by the investors and the FIs, respectively. The sixth and seventh terms represent the consumption of the FIs and the entrepreneurs who exit from the business in period $t$, respectively.

\subsection{Equilibrium Condition}

An equilibrium consists of a set of prices, $\left\{R\left(s^{t}\right), R_{F}\left(s^{t}\right), R_{E}\left(s^{t}\right), W\left(s^{t}\right), W_{F}\left(s^{t}\right)\right.$, $\left.W_{E}\left(s^{t}\right), Q\left(s^{t}\right), R_{F}\left(s^{t+1} \mid s^{t}\right), R_{E}\left(s^{t+1} \mid s^{t}\right), Z_{F}\left(s^{t+1} \mid s^{t}\right), Z_{E}\left(s^{t+1} \mid s^{t}\right)\right\}_{t=0}^{\infty}$, and the allocations $\left\{\left\{\bar{\omega}_{F, i}\left(s^{t+1} \mid s^{t}\right)\right\}_{i=1}^{\infty}\right\}_{t=0}^{\infty},\left\{\left\{\bar{\omega}_{E, j_{i}}\left(s^{t}\right)\right\}_{j_{i}=1}^{\infty}\right\}_{t=0}^{\infty},\left\{\left\{N_{F, i}\left(s^{t}\right)\right\}_{i=1}^{\infty}\right\}_{t=0}^{\infty},\left\{\left\{N_{E, j_{i}}\left(s^{t}\right)\right\}_{j_{i}=1}^{\infty}\right\}_{t=0}^{\infty}$ $\left.\left\{Y\left(s^{t}\right), C\left(s^{t}\right), D\left(s^{t}\right), I\left(s^{t}\right), K\left(s^{t}\right), H\left(s^{t}\right), \Pi\left(s^{t}\right)\right\}\right\}_{t=0}^{\infty}$, for a given government policy $\left\{G\left(s^{t}\right), T\left(s^{t}\right)\right\}_{t=0}^{\infty}$, realization of exogenous variables $\left\{\varepsilon_{A}\left(s^{t}\right), \varepsilon_{N_{F}}\left(s^{t}\right), \varepsilon_{N_{E}}\left(s^{t}\right)\right\}_{t=0}^{\infty}$ and initial conditions $\left\{N_{F, i,-1}\right\}_{i=1}^{\infty},\left\{N_{E, j_{i},-1}\right\}_{j_{i}=1}^{\infty},\left\{K_{-1}\right\}$ such that for all $t, i, j_{i}$ and $h$ :

$(i)$ the household maximizes its utility given the prices;

(ii) the FIs maximize their profits given the prices;

(iii) the entrepreneurs maximize their profits given the prices;

(iv) final goods producers maximize their profits given the prices;

$(v)$ capital goods producers maximize their profit given the prices;

(vi) the government budget constraint holds; and

(vii) markets clear.

\section{Quantitative Analysis}

In this section, we formulate the quantitative analysis based on a model calibrated to the U.S. economy, which we call the baseline model. We first investigate the properties 
of the cost-of-funds curve, setting the credit market parameters, such as monitoring cost $\left(\mu_{F}\right.$ and $\left.\mu_{E}\right)$ and riskiness $\left(\sigma_{F}\right.$ and $\left.\sigma_{E}\right)$, equal to those in the U.S. data. As illustrated in Figures 5, 6, 7, and 8, the size of these parameters are important determinant of the relationship between the net worths and the external finance premium. We show that these parameters are different across the FIs and the entrepreneurs, making the external finance premium more sensitive to a change in the FIs' net worth.

Next, we explore the dynamics of the baseline model in response to various macroeconomic shocks. To this end, we calculate the non-stochastic steady state of the model, log-linearize the first order condition (25) shown in Appendix A together with equilibrium conditions (10), (11), (13), (14), (17), (18), (19), (20), (22) and (24) around the non-stochastic steady state, and compute the model's equilibrium time path after exogenous shocks.

To explore the role of the FIs' net worth in the model's dynamics, we develop an alternative model that abstracts from the FIs' credit friction. We call this alternative model the "BGG model." ${ }^{21}$ This BGG model can be interpreted as a special case of our baseline model in which the credit friction stems from the IF contract is negligibly small.

\subsection{Calibration}

We borrow several parameter values from BGG (1999) for our baseline model. These include the quarterly discount factor $\beta$, the labor supply elasticity $\eta$, the capital share $\alpha$, the quarterly depreciation rate $\delta$, and the steady state share of government expenditure in total output $G / Y .^{22}$ We set the values for the six parameters that are related to the credit contracts: the lenders' monitoring cost in the IF contract $\mu_{F}$, the lenders' monitoring cost in the FE contract $\mu_{E}$, the FI's riskiness $\sigma_{F}$, the entrepreneurial riskiness $\sigma_{E}$, the FIs' survival rate $\gamma_{F}$, and the entrepreneurs' survival rate $\gamma_{E}$, so that the values are consistent with the following six equilibrium conditions. ${ }^{23}$ These are:

1. the spread between the return to capital and the risk-free rate, $R_{E}-R$, equals 200 basis points annually,

2. the ratio of net worth held by the FIs to capital, $N_{F} / Q K$, is 0.1 , which is close to the historical average of the U.S. data, ${ }^{24}$

3. the ratio of net worth held by the entrepreneurs to capital, $N_{E} / Q K$, is 0.5 ,

\footnotetext{
${ }^{21}$ See Appendix B for the first order conditions in our "BGG model."

${ }^{22}$ See Appendix $\mathrm{C}$ for the details of parameter values.

${ }^{23}$ See Appendix D for details.

${ }^{24}$ We calculate the steady state value of $N_{F} / Q K$ based on the Flow of Fund data, released by the Federal Reserve Board. In obtaining the value for $N_{F} / Q K$, we first calculate the historical series of the sum of corporate equities and noncorporate business equities issued by financial sectors divided by total liability and equities of nonfinancial business sector, and then calculate the historical average of the series from 1990 to 2005.
} 
4. the annualized failure rate of the FIs is $3 \%,{ }^{25}$

5. the annualized failure rate of the entrepreneurs is $3 \%$, and

6. the ratio of the spread between the FIs' loan rate and the FIs' borrowing rate, $Z_{E}-Z_{F}$, to the spread between the FIs' borrowing rate and the risk-free rate, $Z_{F}-R$, equals $337 \mathrm{bps} / 58 \mathrm{bps} .^{26}$

The equilibrium conditions (1), (3), and (5) above are taken from BGG (1999).

The obtained parameters are asymmetric across the FIs and the entrepreneurs, reflecting the difference in the size of net worths, $N_{E}$ and $N_{F}$, and the borrowing rates, $Z_{E}$ and $Z_{F}$, across the two sectors. As for the monitoring cost, the value of $\mu_{F}$ is five times larger than the value of $\mu_{E}$, implying that the reduction of the FIs' expected profit is larger under a failure of the FIs than that of the entrepreneurs. Other things being equal, therefore, the external finance premium is more sensitive to a change in the FIs' net worth than a change in the entrepreneurial net worth. ${ }^{27}$

As for the riskiness, we find that the value of $\sigma_{F}$ is one-third of that of $\sigma_{E}$. As displayed in Figures 7 and 8, since the uncertainty associated with the FIs' idiosyncratic productivity shock is smaller than that associated with the entrepreneurial idiosyncratic productivity shock, the expected default cost in the IF contracts is relatively smaller. These parameter values reflect the fact that, the observed spread between the FIs' borrowing rate and the risk-free rate is narrower than the spread between the entrepreneurial borrowing rate and the FIs' borrowing rate $Z_{F}-R<Z_{E}-Z_{F}$.

\subsection{Cost-of-Funds Curve in the U.S. economy}

In Figure 9, we display the cost-of-funds curve of the U.S. economy, using the credit market technology parameters calibrated above. The vertical blue line depicts the share of the FIs' net worth at the steady state.

Three features of the curve are important in determining the effect of the net-worth distribution on the external finance premium. First, the curve is U-shaped and the FIs' net worth share at the steady state lies below the bottom of the curve. This implies

\footnotetext{
${ }^{25}$ Here, we set the failure rate of the FIs equals to that of the entrepreneurs based on the observation of the time path of the CDS premium in the U.S. economy including the periods of the recent crisis.

${ }^{26}$ We employ the BAA yield as a proxy for $Z_{E}$, the 3-month CD rate as a proxy for $Z_{F}$, and Treasury Bill 3-month rate as a proxy for $R$, and take their averages from 1980 to 2008 to generate the steady state relationship for the ratio $\left(Z_{E}-Z_{F}\right) /\left(Z_{F}-R\right)$

${ }^{27}$ Our calibrated monitoring cost in the FE contracts $\mu_{E}$ is 0.016 , which is smaller than 0.12 , the value of corresponding parameter reported in BGG (1999). One possible reason behind this result is that our model consists of the credit friction associated with the FIs as well as that associated with the entrepreneurs, and the spread between the return to capital and the risk-free rate $R_{E}-R$ is created by these two credit frictions. By contrast, in the model of BGG (1999), the credit friction of the entrepreneurs alone explains the same size of the spread.
} 
that the external finance premium is reduced if the FIs' net worth share is incrementally increased in compensation for a reduction of the entrepreneurial net-worth share. Since the two entities' net worths work complementarily, under the economic environment where the FIs' net worth is scarce at the steady state, a rise in the external finance premium brought on by an increase in the entrepreneurs default costs (a channel through term [2] in equation (9)) is dominated by an opposing effect stemming from a decrease in the FIs' default costs (a channel through term [2] in equation (9)).

Second, the U-shaped curve is tilted to the right, implying that an incremental decrease in the FIs' net worth causes a relatively large impact on the external finance premium, leaving aside the influence stemming from the cross-sectional distribution of the net worth discussed above. Because the FIs' monitoring cost $\mu_{F}$ is higher than the entrepreneurs's monitoring cost $\mu_{E}$, even if the default probabilities are the same across the two borrowing sectors, the external finance premium reacts more sensitively to a change in the FIs' default than that in the entrepreneurs' default.

Third, the bottom of the U-shaped curve is obtained at the point where the FIs' net worth share is about 20\%. Because the FIs' riskiness $\sigma_{F}$ is smaller than the entrepreneurs' riskiness $\sigma_{E}$, other things being equal, the default probability of the FIs is smaller than that of the entrepreneurs. As a result, the cross-sectional net-worth distribution that yields the thinnest external finance premium is located below $50 \%$, where the net worth is distributed evenly, and is shifted to the left.

\subsection{Dynamic behavior of chained credit contract model}

Based on the model with cost-of-funds curve calibrated to the U.S. economy, we investigate the model's dynamics in response to exogenous disturbances. The dynamics of equilibrium responses are computed as linear approximations around the non-stochastic steady states. As seen below, the endogenous developments in two entities' net worths, the FIs' net worth and the entrepreneurial net worth, amplify and propagate the effects of the exogenous disturbances through the credit market imperfection (financial accelerator effect).

To illustrate the role of the FI sector in the financial accelerator effect, we compute the impulse responses of variables under the BGG model as well as those under our baseline model. The credit market imperfection in the BGG model arises only from the FE contracts, since it abstracts from the credit-constrained FIs. Comparison between the two models helps separate the financial accelerator effect attributed to the IF contract and that attributed to the FE contract. ${ }^{28}$

\footnotetext{
${ }^{28}$ The departure of our BGG model from the original model developed in BGG (1999) are twofold: (i) all goods prices are flexible, and $(i i)$ parameter values are set so that they are comparable to the settings of our baseline model. That is, the parameter values regarding the credit contracts between the FIs and the entrepreneurial sector, $\sigma_{E}, \mu_{E}$, and $n_{E}$, and the steady state return to capital $R_{E}$ are set equal to the corresponding values in our baseline model. Other parameters in the BGG model are recalibrated so as to satisfy the evolving equation of the entrepreneurial net worth, that corresponds to
} 


\section{Shocks to the net worth}

Figure 10 shows the economy's responses to an unexpected, once-and-for-all disruption of the net worth by $0.01 \%$ of steady state GDP in period $t=0$ for our baseline model and the BGG model. The solid line with black circles and the dotted line depict the economic response under the baseline model to the disruption of the FIs' net worth and the entrepreneurial net worth, respectively. The solid line depicts the economic response under the BGG model to the disruption of the entrepreneurial net worth.

The exogenous disruption in the FIs' net worth depresses the economy through the financial accelerator effect. At impact, it increases the default probabilities in the credit contracts reflecting severe credit frictions. Because the participation constraints of the investor need to hold with higher defaults costs, the external finance premium $\mathrm{E}_{t}\left\{R_{E}\left(s^{t+1}\right)\right\} R\left(s^{t}\right)^{-1}$ rises. This rise in the external finance premium indicates that the investment becomes more costly, leading to a decline in investment demand $I\left(s^{t}\right)$. Since the demand for capital goods weakens, the capital goods price $Q\left(s^{t}\right)$ drops. As shown in equations (10) and (11), both higher default costs and a lower capital goods price reduce the earnings from the credit contracts for both the FIs and the entrepreneurs, causing the two entities' net worth to endogenously decline and depressing the economy further.

The economic dynamics caused by the disruption of the entrepreneurial net worth are qualitatively similar to those caused by shocks to the FIs' net worth. A higher external finance premium stemming from a higher default probability dampens investment, reduces the capital goods price, and endogenously deteriorates the net worth of the two entities, causing a further decline in investment.

\section{Shock to the productivity}

Figure 11 shows the economy's responses to a negative productivity shock in the two models. We consider the case where the productivity of the final goods sector drops in period $t=0$, gradually returning to its steady state at the rate of $\rho_{A}$. The solid line with black circles denotes the response of the baseline model and the dotted line denotes the response of the BGG model.

First of all, as equation (15) suggests, the decline in the productivity decreases the output even if the amounts of production inputs hired for production are unchanged. The financial accelerator effect helps amplify and propagate this shock's impact by reducing mainly capital inputs through the credit market imperfection. Because the lower productivity drives down the ex post discounted return to capital, the investment demand $I\left(s^{t}\right)$ shrinks, leading to a drop in the capital goods price $Q\left(s^{t}\right)$. Similarly to the net-worth shocks, the inflows of the net worth equations (10) and (11) diminish, resulting in the deterioration of the two entities' net worth. As leverage subsequently rises, default

equation (11) in our baseline model, and the default probability of the entrepreneurs, that corresponds to the condition 5 in calibration section in our baseline model, at the steady state. 
costs increase. Consequently, the external finance premium $\mathrm{E}_{t}\left\{R_{E}\left(s^{t+1}\right)\right\} R\left(s^{t}\right)^{-1}$ rises, resulting in a further decline of economic activity.

\section{Comparison between the shock to the FIs' net worth and that of the entrepreneurial net worth}

It is of importance to stress the cross-sectional difference in the way that the baseline model responds to the net-worth shock. As illustrated in Figure 10, a disruption of equal size to the net worth of the entrepreneurs and the FIs results in a higher increase in the external finance premium $\mathrm{E}_{t}\left\{R_{E}\left(s^{t+1}\right)\right\} R\left(s^{t}\right)^{-1}$ and a larger decline in investment $I\left(s^{t}\right)$ when the disruption occurs in the FIs sector rather than in the entrepreneurial sector.

The key feature of the model that delivers this result is the net-worth distribution across the FIs and the entrepreneurs in the U.S. economy. As shown in Figure 9, the actual distribution is biased toward the entrepreneurial sector at the steady state, indicating that a negative deviation of the FIs' net worth from the steady-state value causes an increase in the external finance premium than the negative deviation of the entrepreneurial net worth of the same size. Consequently, a disruption in the FIs' net worth is more easily reflected in a rise in the external finance premium $\mathrm{E}_{t}\left\{R_{E}\left(s^{t+1}\right)\right\} R\left(s^{t}\right)^{-1}$ around the steady state, yielding a disproportionately large impact on the aggregate economy in the dynamics compared with the case of a disruption in the entrepreneurial net worth. The high monitoring cost of the FIs $\mu_{F}$ makes this sectoral asymmetry in economic responses even larger.

\section{Comparison between the baseline model and the BGG model}

The quantitative implications of chained credit contracts are displayed in Figures 10 and 11. For the same size of disruption to the entrepreneurial net worth and productivity, the baseline model implies a larger economic downturn than that generated by the BGG model. $^{29}$

The presence of chained credit contracts plays the pivotal role in generating this difference in the model's implication. First, since the IF and FE credit contracts are chained, the earnings from the credit contracts $V_{F}\left(s^{t}\right)$ and $V_{E}\left(s^{t}\right)$ comove in response to exogenous shocks studied here. Consequently, these adverse shocks that hit either or both of the two sectors result in the deterioration of the net worth of both entities $N_{F}\left(s^{t}\right)$ and $N_{E}\left(s^{t}\right) .{ }^{30}$ Second, as expressed in equation (9), the disruption of the two net worths works complementarily in increasing the external finance premium $\mathrm{E}_{t}\left\{R_{E}\left(s^{t+1}\right)\right\} R\left(s^{t}\right)^{-1}$, reinforcing

\footnotetext{
${ }^{29}$ For sensitivity analysis, we compare our baseline model with one other BGG model that is parameterized in a different manner from the one examined in this section. We set the steady state risk-free rate $R$ equalized the same across the models, and set the steady state return to capital $R_{E}$ different across the models. The economic responses of the BGG model is little changed by this alternative parametrization.

${ }^{30}$ See also Chen (2001). In the model, the presence of asymmetric information in the credit market makes the bank's net worth and the entrepreneurial net worth inerrelated from each other, generating a larger economic response to a shock to the bank's net worth.
} 
the financial accelerator effect on each other. As a result, in the baseline model, a disruption of net worth in the entrepreneurial sector, for instance, causes a higher external finance premium than would happen otherwise, dampening investment more than in the BGG model.

\section{Role of the net-worth distribution and the size of monitoring costs}

Lastly, we see how the cross-sectional net-worth distribution affects the financial accelerator effect. To this end, we construct an additional alternative model and compare the model with our baseline model. In this alternative model, we hypothetically alter the cross-sectional net-worth distribution from the baseline model such that the FIs and the entrepreneurs own an equal amount of the net worth at the steady state, that is $n_{F}=n_{E}$.

Figure 12 displays the impulse response of investment and the external finance premium to a productivity shock, an entrepreneurial net-worth shock, and a shock to the FIs' net worth under the alternative models as well as the baseline model. Clearly, the net-worth distribution of the FIs and entrepreneurs plays the quantitatively important role in amplifying and propagating the exogenous shocks. When the net worths are equally distributed across the two borrowing entities, the economic downturns due to the productivity shock and the FIs' net-worth shocks are mitigated. This is because complementarity between the two net worths mitigates the financial accelerator effect, as is displayed in Figure 9. By contrast, the downturn due to the entrepreneurial net-worth shock becomes substantially larger than that in the baseline model.

\section{Conclusion}

Empirical evidence suggests that the net worth in the FIs matters for the macroeconomic activity. Based on the financial accelerator model of Bernanke, et al. (1999), we developed a dynamic general equilibrium model in which the FIs as well as the entrepreneurs are subject to credit constraints and finance their economic activities by their net worth and external funding. In this model, the net worth of the two entities influences the external finance premium and aggregate investment.

Based on a model calibrated to the U.S. economy, we investigated the role played by the FIs' net worth in economic dynamics. In particular, we asked how the net worth held by the financial sector differs from that held by the non-financial sector. Our model delivered two features regarding the FIs' net worth that demonstrate that the two entities' net worth works differently in the aggregate economy. First, the relative size of FIs' net worth over entrepreneurial net worth, namely the distribution of net worth, matters for the magnitude of financial accelerator effect. Second, under the current distribution of the net worth in the U.S. economy, a shock to the FIs' net worth has greater aggregate impacts than that to entrepreneurial net worth. Behind those results, there is a fact that 
the cross-sectional distribution of the net worth is unbalanced and the FIs' net worth is relatively scarce in the United States.

Our results have policy implications regarding the intensified Basel bank regulations that have progressed after the financial crisis. ${ }^{31}$ In those regulatory frameworks, the FIs' net worth is expected to play the pivotal role in achieving the financial stability. Along this line, our results suggest that the regulatory framework that protects banks' net worth from irrational exuberance or that fosters accumulation of banks' net worth may be beneficial from the macroeconomic stability purpose.

\footnotetext{
${ }^{31}$ In Hirakata, Sudo, and Ueda (2013), we extend the current model to a New Keynesian sticky price framework and investigate the implications of unconventional policies implemented during the Great Recession, including capital injections to the FIs and to the entrepreneurs. Relatedly, in Hirakata, Sudo, and Ueda (2011) we examine the relative significance of shocks to the FIs compared with other shocks, including technology shocks, in explaining the U.S. business cycles. The focus of the current paper is different from these studies. In the current paper, we specifically focus on analysis of the distinct role played by the FIs' net worth, which differs from the role played by the entrepreneurial net worth, and the implication of the net worth distribution across sectors to the macroeconomy.
} 


\section{A First Order Conditions for the Credit Contracts}

Arranging the first order conditions of the maximization problem of type $i$ FI is given by the following equation. From the reason discussed above, we drop subscript $i$ and $j_{i}$.

$$
\begin{aligned}
& 0=\sum_{s^{t+1} \mid s^{t}} \Pi\left(s^{t+1} \mid s^{t}\right)\left\{\left(1-\Gamma_{F}\left(\bar{\omega}_{F}\left(s^{t+1} \mid s^{t}\right)\right)\right) \Phi_{E}\left(\bar{\omega}_{E}\left(s^{t}\right)\right) R_{E}\left(s^{t+1} \mid s^{t}\right)\right. \\
& +\frac{\Gamma_{F}^{\prime}\left(\bar{\omega}_{F}\left(s^{t+1} \mid s^{t}\right)\right)}{\Phi_{F}^{\prime}\left(\bar{\omega}_{F}\left(s^{t+1} \mid s^{t}\right)\right)} \Phi_{F}\left(\bar{\omega}_{F}\left(s^{t+1} \mid s^{t}\right)\right) \Phi_{E}\left(\bar{\omega}_{E}\left(s^{t}\right)\right) R_{E}\left(s^{t+1} \mid s^{t}\right) \\
& -\frac{\Gamma_{F}^{\prime}\left(\bar{\omega}_{F}\left(s^{t+1} \mid s^{t}\right)\right)}{\Phi_{F}^{\prime}\left(\bar{\omega}_{F}\left(s^{t+1} \mid s^{t}\right)\right)} R\left(s^{t}\right) \\
& +\frac{\left\{1-\Gamma_{F}\left(\bar{\omega}_{F}\left(s^{t+1} \mid s^{t}\right)\right)\right\} \Phi_{E}^{\prime}\left(\bar{\omega}_{E}\left(s^{t}\right)\right)}{\Gamma_{E}^{\prime}\left(\bar{\omega}_{E}\left(s^{t}\right)\right)}\left(1-\Gamma_{E}\left(\bar{\omega}_{E}\left(s^{t}\right)\right)\right) R_{E}\left(s^{t+1} \mid s^{t}\right) \\
& \left.+\frac{\Gamma_{F}^{\prime}\left(\bar{\omega}_{F}\left(s^{t+1} \mid s^{t}\right)\right) \Phi_{F}\left(\bar{\omega}_{F}\left(s^{t+1} \mid s^{t}\right)\right) \Phi_{E}^{\prime}\left(\bar{\omega}_{E}\left(s^{t}\right)\right)}{\Phi_{F}^{\prime}\left(\bar{\omega}_{F}\left(s^{t+1} \mid s^{t}\right)\right) \Gamma_{E}^{\prime}\left(\bar{\omega}_{E}\left(s^{t}\right)\right)}\left(1-\Gamma_{E}\left(\bar{\omega}_{E}\left(s^{t}\right)\right)\right) R_{E}\left(s^{t+1} \mid s^{t}\right)\right\}
\end{aligned}
$$

for $\forall j_{i}$

where

$$
\begin{aligned}
\Gamma_{F}\left(\bar{\omega}_{F}\left(s^{t+1} \mid s^{t}\right)\right) & \equiv \int_{0}^{\bar{\omega}_{F}\left(s^{t+1} \mid s^{t}\right)} \omega_{F} d F_{F}\left(\omega_{F}\right)+\bar{\omega}_{F}\left(s^{t+1} \mid s^{t}\right) \int_{\bar{\omega}_{F}\left(s^{t+1} \mid s^{t}\right)}^{\infty} d F_{F}\left(\omega_{F}\right), \text { and } \\
\Gamma_{E}\left(\bar{\omega}_{E}\left(s^{t}\right)\right) & \equiv \int_{0}^{\bar{\omega}_{E}\left(s^{t}\right)} \omega_{E} d F_{E}\left(\omega_{E}\right)+\bar{\omega}_{E}\left(s^{t}\right) \int_{\bar{\omega}_{E}\left(s^{t}\right)}^{\infty} d F_{E}\left(\omega_{E}\right) .
\end{aligned}
$$

As we assume that both $\omega_{F}\left(s^{t}\right)$ and $\omega_{E}\left(s^{t}\right)$ obey different log-normal distributions, with $E\left(\omega_{F}\left(s^{t}\right)\right)=1$ and $E\left(\omega_{E},\left(s^{t}\right)\right)=1$, respectively, denoting the variance of $\log \omega_{F}\left(s^{t}\right)$ and $\log \omega_{E}\left(s^{t}\right)$ by $\sigma_{F}^{2}$ and $\sigma_{E}^{2}$, we have

$$
\begin{aligned}
\Gamma_{F}\left(\bar{\omega}_{F}\left(s^{t+1} \mid s^{t}\right)\right)= & \frac{1}{\sqrt{2 \pi}} \int_{-\infty}^{\frac{\log \bar{\omega}_{F}\left(s^{t+1} \mid s^{t}\right)-0.5 \sigma_{F}^{2}}{\sigma_{F}}} \exp \left(-\frac{v_{F}^{2}}{2}\right) d v_{F} \\
& +\frac{\bar{\omega}_{F}\left(s^{t+1} \mid s^{t}\right)}{\sqrt{2 \pi}} \int_{\frac{\log \bar{\omega}_{F}\left(s^{t+1} \mid s^{t}\right)+0.5 \sigma_{F}^{2}}{\sigma_{F}}}^{\infty} \exp \left(-\frac{v_{F}^{2}}{2}\right) d v_{F}, \text { and }
\end{aligned}
$$




$$
\begin{aligned}
\Gamma_{E}\left(\bar{\omega}_{E}\left(s^{t}\right)\right)= & \frac{1}{\sqrt{2 \pi}} \int_{-\infty}^{\frac{\log \bar{\omega}_{E}\left(s^{t}\right)-0.5 \sigma_{E}^{2}}{\sigma_{E}}} \exp \left(-\frac{x^{2}}{2}\right) d x \\
& +\frac{\bar{\omega}_{E}\left(s^{t}\right)}{\sqrt{2 \pi}} \int_{\frac{\log \bar{\omega}_{E}\left(s^{t}\right)+0.5 \sigma_{E}^{2}}{\sigma_{E}}}^{\infty} \exp \left(-\frac{v_{E}^{2}}{2}\right) d v_{E} .
\end{aligned}
$$

Similarly, the differentials of $\Gamma_{F}\left(\bar{\omega}_{F}\left(s^{t+1} \mid s^{t}\right)\right)$ and $\Gamma_{E}\left(\bar{\omega}_{E}\left(s^{t}\right)\right)$ with respect to $\bar{\omega}_{F}\left(s^{t+1} \mid s^{t}\right)$ and $\bar{\omega}_{E}\left(s^{t}\right)$ are given by

$$
\begin{aligned}
\Gamma_{F}^{\prime}\left(\bar{\omega}_{F}\left(s^{t+1} \mid s^{t}\right)\right)= & \frac{1}{\sqrt{2 \pi} \bar{\omega}_{F}\left(s^{t+1} \mid s^{t}\right) \sigma_{F}} \exp \left(-.5\left(\frac{\log \bar{\omega}_{F}\left(s^{t+1} \mid s^{t}\right)-0.5 \sigma_{F}^{2}}{\sigma_{F}}\right)^{2}\right) d x \\
& +\frac{1}{\sqrt{2 \pi}} \int_{\frac{\log \bar{\omega}_{F}\left(s^{t+1} \mid s^{t}\right)+0.5 \sigma_{F}^{2}}{\sigma_{F}}}^{\infty} \exp \left(-\frac{v_{F}^{2}}{2}\right) d v_{F} \\
& -\frac{1}{\sqrt{2 \pi} \sigma_{F}} \exp \left(-\frac{\left.\left(\frac{\log \bar{\omega}_{F}\left(s^{t+1} \mid s^{t}\right)+0.5 \sigma_{F}^{2}}{\sigma_{F}}\right)^{2}\right)}{2} d x,\right. \text { and } \\
\Gamma_{E}^{\prime}\left(\bar{\omega}_{E}\left(s^{t}\right)\right)= & \frac{1}{\sqrt{2 \pi} \bar{\omega}_{E}\left(s^{t}\right) \sigma_{E}} \exp \left(-.5\left(\frac{\left.\left.\log \bar{\omega}_{E}\left(s^{t}\right)-0.5 \sigma_{E}^{2}\right)^{2}\right) d x}{\sigma_{E}}\right.\right. \\
& +\frac{1}{\sqrt{2 \pi}} \int_{\frac{\log \bar{\omega}_{E}\left(s^{t}\right)+0.5 \sigma_{E}^{2}}{\sigma_{E}}}^{\infty} \exp \left(-\frac{v_{E}^{2}}{2}\right) d v_{E} \\
& -\frac{1}{\sqrt{2 \pi} \sigma_{E}} \exp \left(-.5\left(\frac{\log \bar{\omega}_{E}\left(s^{t}\right)+0.5 \sigma_{E}^{2}}{\sigma_{E}}\right)^{2}\right) d x .
\end{aligned}
$$




\section{B Equilibrium Conditions of the BGG Model}

The only difference between our baseline model and the "BGG model" is that the latter model abstracts from the credit friction in the IF contract. Since only entrepreneurs are credit constrained, the equilibrium conditions in the BGG model are given by equations (11), (13), (14), (17), (18), (20), and (22) as well as the following three equations that correspond to equations (25), (9), and (24) in the benchmark model:

$$
\begin{gathered}
0=\sum_{s^{t+1} \mid s^{t}} \Pi\left(s^{t+1} \mid s^{t}\right)\left(1-\Gamma_{E}\left(\bar{\omega}_{E}\left(s^{t+1} \mid s^{t}\right)\right)\right) R_{E}\left(s^{t+1} \mid s^{t}\right) \\
+\frac{\Gamma_{E}^{\prime}\left(\bar{\omega}_{E}\left(s^{t+1} \mid s^{t}\right)\right)}{\Phi_{E}^{\prime}\left(s^{t+1} \mid s^{t}\right)} \Phi_{E}\left(s^{t+1} \mid s^{t}\right) R_{E}\left(s^{t+1} \mid s^{t}\right)-\frac{\Gamma_{E}^{\prime}\left(\bar{\omega}_{E}\left(s^{t+1} \mid s^{t}\right)\right)}{\Phi^{\prime}\left(s^{t+1} \mid s^{t}\right)} \Phi_{E}\left(s^{t+1} \mid s^{t}\right) R\left(s^{t}\right) \\
Y\left(s^{t}\right)=C\left(s^{t}\right)+I\left(s^{t}\right)+G\left(s^{t}\right) \\
\quad+\left(\mu_{E} \int_{0}^{\bar{\omega}_{E}} \omega_{E} d F_{E}\left(\omega_{E}\right)\right) R_{E}\left(s^{t}\right) Q\left(s^{t-1}\right) K\left(s^{t-1}\right)+C^{E}\left(s^{t}\right)
\end{gathered}
$$

with

$$
\begin{gathered}
C_{E}\left(s^{t}\right) \equiv\left(1-\Gamma_{E}\left(\bar{\omega}_{E}\left(s^{t+1}\right)\right)\right) R_{E}\left(s^{t+1}\right) Q\left(s^{t}\right) K\left(s^{t}\right) \\
{\left[\int_{\bar{\omega}_{E}\left(s^{t+1} \mid s^{t}\right)}^{\infty} \bar{\omega}_{E}\left(s^{t+1} \mid s^{t}\right) d F_{E}\left(\omega_{E}\right)-\mu_{E}\left(\mu_{E} \int_{0}^{\bar{\omega}_{E}} \omega_{E} d F_{E}\left(\omega_{E}\right)\right)\right] R_{E}\left(s^{t+1} \mid s^{t}\right) Q\left(s^{t}\right) K\left(s^{t}\right)} \\
=R\left(s^{t}\right)\left(Q\left(s^{t}\right) K\left(s^{t}\right)-N_{E}\left(s^{t}\right)\right) .
\end{gathered}
$$




\section{Parameterization I}

This appendix provides parameterization of the variables associated with the household, wholesalers, capital goods producers, retailers, final goods producers, and government. Following earlier studies including BGG (1999) and CMR (2004), we choose conventional values for these parameters.

\begin{tabular}{ccc} 
& \multicolumn{2}{c}{ Parameters $^{32}$} \\
\hline Parameter & Value & Description \\
\hline$\beta$ & .99 & Discount Factor \\
$\delta$ & .025 & Depreciation rate \\
$\alpha$ & .35 & Capital share \\
$R$ & $.99^{-1}$ & Risk-free rate \\
$\eta$ & 3 & Elasticity of labor \\
$\chi$ & .3 & Utility weight on leisure \\
$\kappa$ & 2.5 & Investment adjustment cost \\
$\rho_{a}$ & .85 & Autoregressive parameters of productivity shock
\end{tabular}

\footnotetext{
${ }^{32}$ Figures are quarterly unless otherwise stated.
} 


\section{Parameterization II}

This appendix provides parameterization of the variables that are related to the credit contracts among investors, FIs and entrepreneurs. We choose six parameters so that they are consistent with the equilibrium conditions (1), (2), (5), (6), (25), (10) and (11) evaluated using the steady state values shown in the upper table.

Steady state conditions

\begin{tabular}{ccc}
\hline Condition & Value & Description \\
\hline$R_{E}-R$ & $0.02 / 4$ & Return to capital minus the risk-free rate \\
$F\left(\bar{\omega}_{F}\right)$ & $0.03 / 4$ & Default probability in the IF contract \\
$F\left(\bar{\omega}_{E}\right)$ & $0.03 / 4$ & Default probability in the FE contract \\
$n_{F}$ & 0.1 & FIs' net worth ratio \\
$n_{E}$ & 0.5 & Entrepreneurial net worth ratio \\
$\left(Z_{E}-Z_{F}\right) /\left(Z_{F}-R\right)$ & $337 / 58$ & Spread ratio between FIs' lending and FIs' borrowing
\end{tabular}

Calibrated parameters ${ }^{33}$

\begin{tabular}{ccc}
\hline Parameter & Value & Description \\
\hline$\mu_{F}$ & 0.0784 & Monitoring cost associated with FIs \\
$\mu_{E}$ & 0.0158 & Monitoring cost associated with entrepreneurs \\
$\sigma_{F}$ & 0.0916 & S.E. of FIs' idiosyncratic productivity \\
$\sigma_{E}$ & 0.2698 & S.E. of entrepreneurial idiosyncratic productivity \\
$\gamma_{F}$ & 0.9624 & Survival rate of FIs \\
$\gamma_{E}$ & 0.9838 & Survival rate of entrepreneurs
\end{tabular}

\footnotetext{
${ }^{33}$ Figures are quarterly unless otherwise stated.
} 


\section{References}

[1] Aikman, D. and M. Paustian (2006). "Bank Capital, Asset Prices and Monetary Policy," Bank of England Working Papers 305, Bank of England.

[2] Allen, F. (2001). "Do Financial Institutions Matter?," Journal of Finance, Vol. 56, No. 4, pp.1165-1175.

[3] Bernanke, B. S., (1983). "Nonmonetary Effects of the Financial Crisis in the Propagation of the Great Depression," American Economic Review, Vol. 73, pp. 257-276.

[4] Bernanke, B. S., M. Gertler and S. Gilchrist (1999). "The Financial Accelerator in a Quantitative Business Cycle Framework," in Handbook of Macroeconomics, J. B. Taylor and M. Woodford (eds.), Vol. 1, chapter 21, pp. 1341-1393.

[5] Brzoza-Brzezina, M., K. Marcin and M. Krzysztof (2013) "The anatomy of standard DSGE models with financial frictions," Journal of Economic Dynamics and Control, Vol. 37, pp. 32-51.

[6] Carlstrom, C. T., T. S. Fuerst (1997) "Agency Costs, Net Worth, and Business Fluctuations: A Computable General Equilibrium Analysis," American Economic Review, Vol. 87, No. 5, pp. 893-910.

[7] Chen, N. K. (2001) "Bank Net Worth, Asset Prices and Economic Activity," Journal of Monetary Economics, Vol. 48, No. 2, pp.415-436.

[8] Christiano, L., M. S. Eichenbaum and M. Trabandt (2013). "Unemployment and Business Cycles," NBER Working Papers 19265.

[9] Christiano, L., R. Motto and M. Rostagno (2008) "Shocks, structures or monetary policies? The Euro Area and US after 2001," Journal of Economic Dynamics and Control, Vol. 32, No. 8, pp. 2476-2506.

[10] Christiano, L., R. Motto and M. Rostagno (2013) "Risk Shocks," NBER Working Papers 18682.

[11] Freixas, X. and J. Rochet (2008) "Microeconomics of Banking." Cambridge: MIT Press.

[12] Gerali, A., S. Neri, L. Sessa, and F. Signoretti (2010) "Credit and Banking in a DSGE Model of the Euro Area," Journal of Money, Credit and Banking, Vol. 42, pp. 107-141.

[13] Gertler, M. and P. Karadi (2011) "A Model of Unconventional Monetary Policy," Journal of Monetary Economics, No. 58, pp. 17-34. 
[14] Gertler, M. and N. Kiyotaki (2010) "Financial Intermediation and Credit Policy in Business Cycle Analysis," Handbook of Monetary Economics, edition 1, Vol. 3, chapter 11, pp. 547-599.

[15] Gilchrist, S. and J. V. Leahy (2002) "Monetary Policy and Asset Prices," Journal of Monetary Economics, Vol. 49, No. 1, pp. 75-97.

[16] Goodfriend, M. and B. T. McCallum (2007) "Banking and Interest Rates in Monetary Policy Analysis: A Quantitative Exploration," Journal of Monetary Economics, Vol. 54, No. 5, pp.1480-1507.

[17] Gorton, Gary B. (2008) "The Subprime Panic," Yale ICF Working Paper No. 08-25.

[18] Gorton, Gary B. and Andrew Winton (2003) "Financial Intermediation," in Handbook of the Economics and Finance. G.M. Constantinides, M. Harris, and R.M. Stulz (eds.), Amsterdam: North-Holland. Chapter 8, Vol. 1, part 1. pp.431-552.

[19] Hirakata, N., N. Sudo, and K. Ueda (2013) "Capital Injection, Monetary Policy and Financial Accelerators," International Journal of Central Banking, International Journal of Central Banking, Vol. 9, No 2, pp. 101-145.

[20] Hirakata, N., Sudo, N. Ueda, K. (2011) Do banking shocks matter for the U.S. economy? Journal of Economic Dynamics and Control, No. 35, pp. 2042-2063.

[21] Holmstrom, B. and J. Tirole (1997) "Financial Intermediation, Loanable Funds, and the Real Sector," Quarterly Journal of Economics, Vol. 112, No. 3, pp. 663-691.

[22] Kato, R. S. Kobayashi, and Y. Saita (2011) "Calibrating the Level of Capital: The Way We See It," Journal of Mathematics and System Science Vol. 1.

[23] Kiyotaki, N. and J. Moore (1997) "Credit Cycles," Journal of Political Economy, Vol. 105, No. 2, pp. 211-248.

[24] Klein M. (1971) "A Theory of the Banking Firm," Journal of Money, Credit and Banking, 3, pp.205-218.

[25] Luk, S.K. and D. Vines (2011) "The Stock Market Crash, Lehman Brothers, and Financial Frictions," Draft.

[26] Markovic, B. (2006) "Bank Capital Channels in the Monetary Transmission Mechanism," Bank of England Working Paper 313.

[27] Meh C. and K. Moran (2010) "The Role of Bank Capital in the Propagation of Shocks," Journal of Economic Dynamic and Control, Vol. 34, No. 3, pp. 555-576. 
[28] Miles D. J. Yang, and G. Marcheggiano (2013) "Optimal Bank Capital," Economic Journal, Vol. 123, No. 567, pp. 1-37.

[29] Monti M. (1972) "Deposit, Credit and Interest Rate Determination under Alternative Bank Objectives," in Mathematical Methods in Investment and Finance, G. P. Szego and K. Shell (eds.), Amsterdam: North-Holland.

[30] Van den Heuvel S. J. (2008) "The Welfare Cost of Bank Capital Requirements," Journal of Monetary Economics, Vol. 55, No. 2, pp.298-320.

[31] Zeng, Z. (2011), "A Theory of the Non-Neutrality of Money with Banking Frictions and Bank Recapitalization," Economic Theory, forthcoming.

[32] Zhang, L. (2009) "Bank Capital Regulation, the Lending Channel and Business Cycles," Bundesbank Discussion Paper 33. 


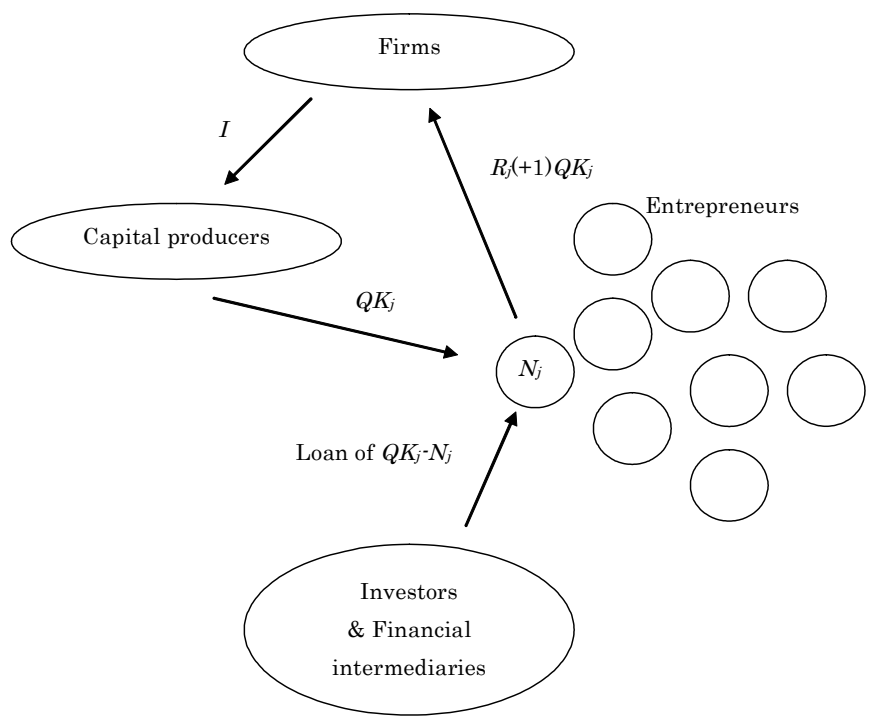

Entrepreneurs'

balance sheet

\begin{tabular}{|c|c|}
\hline \multirow{4}{*}{ Asset } & Debt \\
$Q K$ & $Q K-N$ \\
\cline { 2 - 2 } & Net worth \\
& $N$ \\
\hline
\end{tabular}

Figure 1. Credit contract in the BGG model

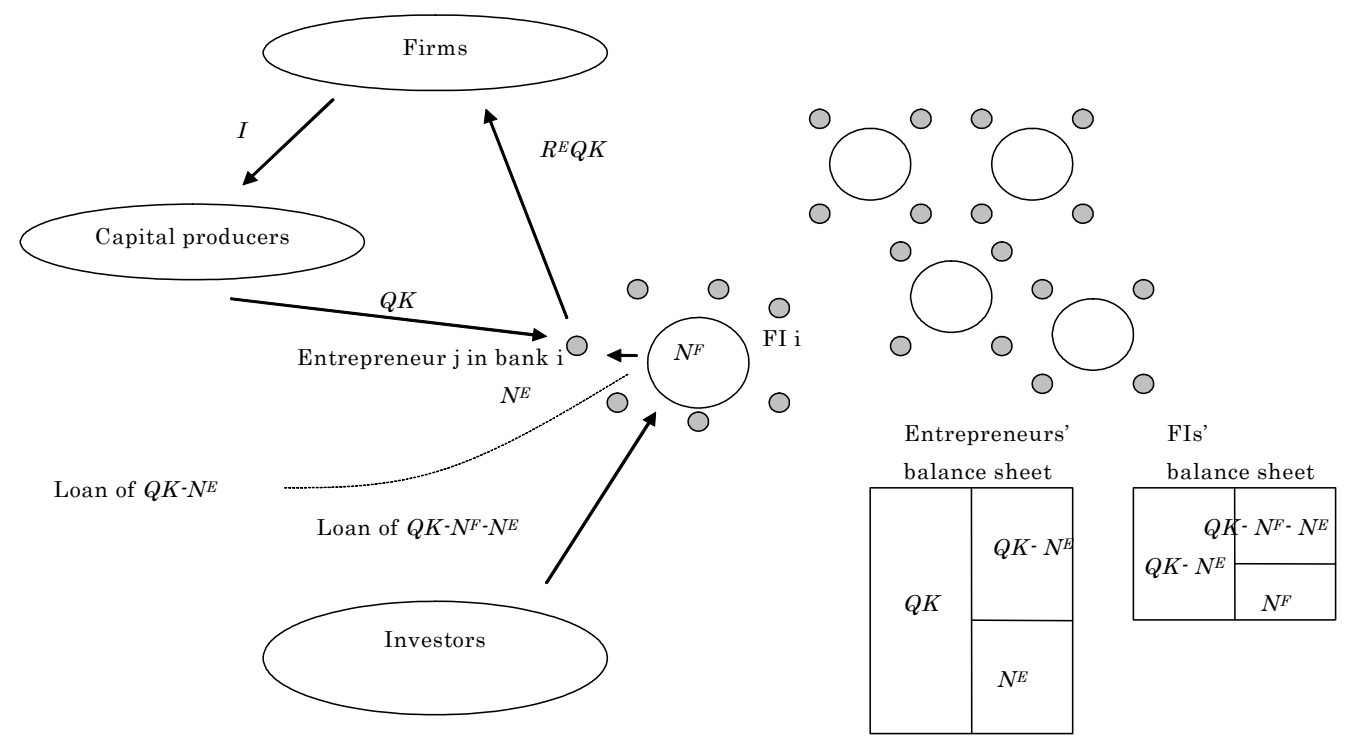

Figure 2. Chained credit contracts in our model 

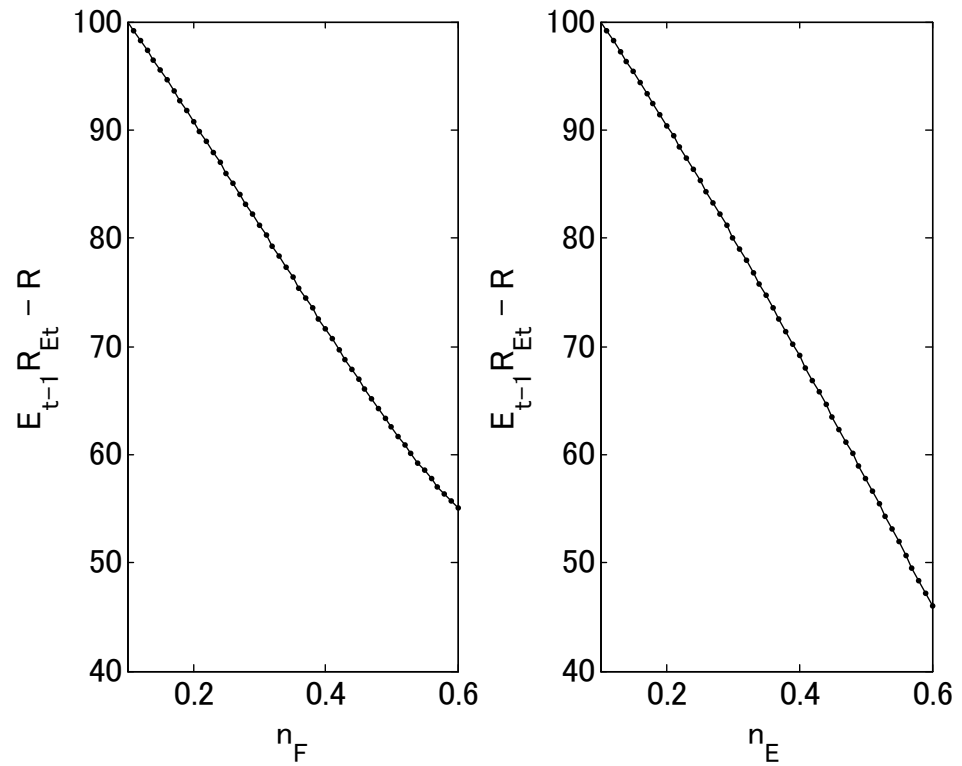

Figure 3. Effect of net worth in the FI sector (left panel) and that in the entrepreneurial sector (right panel) on the external finance premium.

Note: The horizontal axis displays the net worth to capital ratio in each borrowing sector, and the vertical axis displays the external finance premium when one of the two net worth to capital ratios changes while the other net worth to capital ratio is unchanged. 

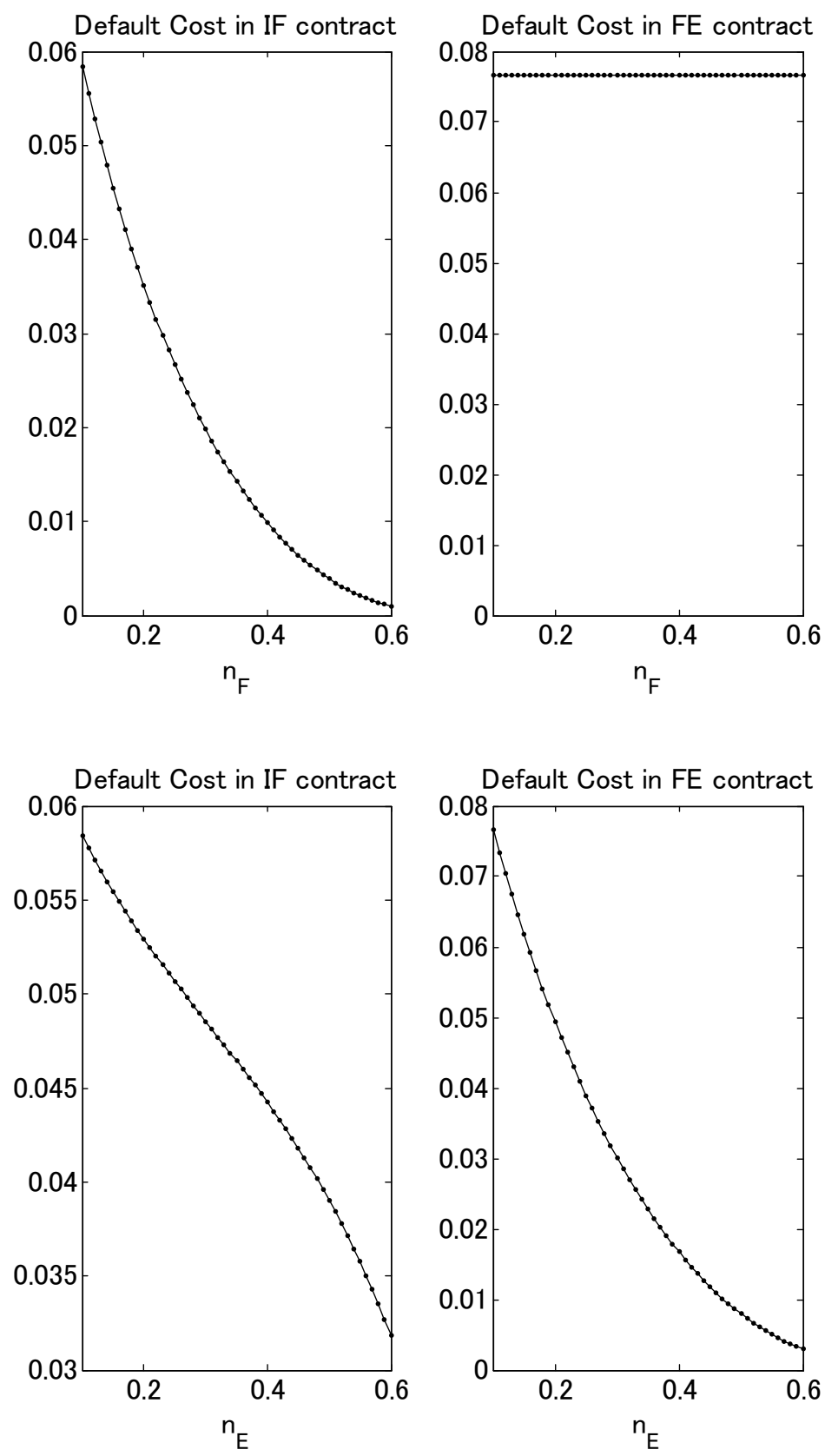

Figure 4. Effects of borrowers' net worth on the expected default cost.

Note: The horizontal axis displays the net worth to capital ratio in each borrowing sector, and the vertical axis displays the expected default cost in the IF contract and the FE contract when one of the two net worth to capital ratios changes while the other net worth to capital ratio is unchanged. 


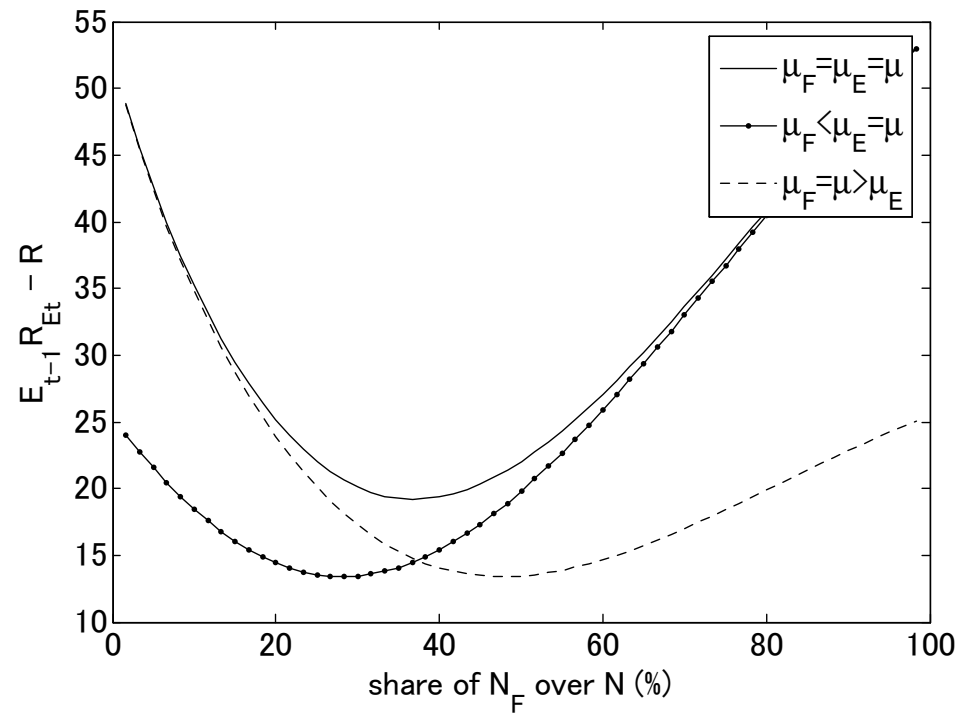

Figure 5. Effects of net worth distribution and monitoring cost on the external finance premium

Note: The horizontal axis displays the share of the FIs' net worth over the total net worths, and the vertical axis displays the corresponding external finance premium. The solid line, the solid line with black circles, and the dashed line display the case when the monitoring costs are the same across both the FIs and the entrepreneurs, when the FIs' monitoring cost is smaller than the entrepreneurial monitoring cost, and when the FIs' monitoring cost is larger than the entrepreneurial monitoring cost, respectively. 

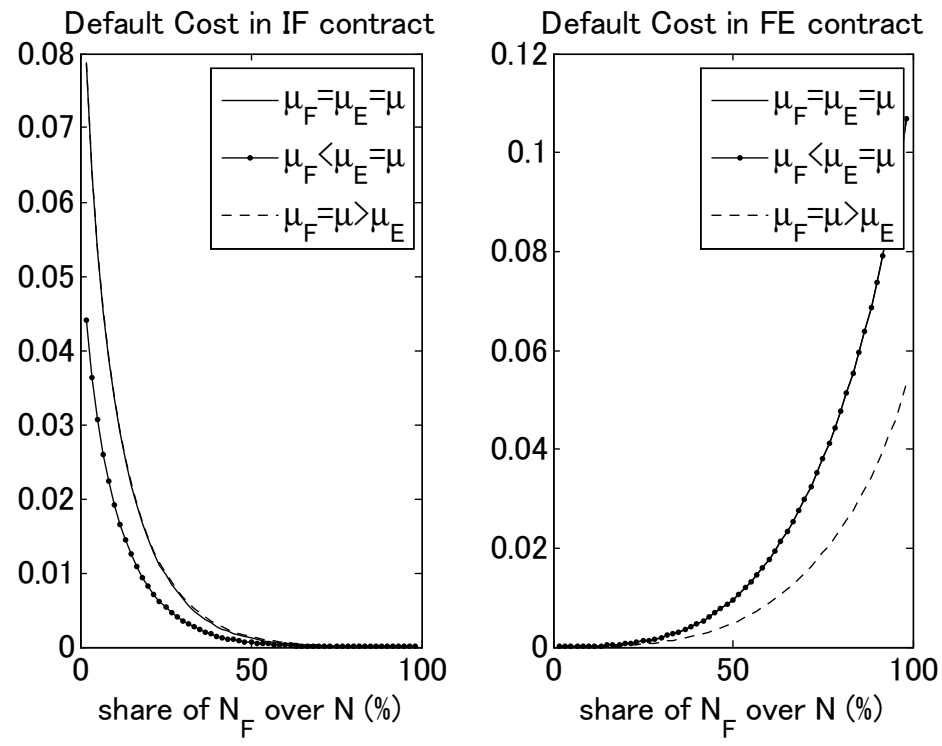

Figure 6. Effects of net worth distribution and monitoring cost on default cost

Note: The horizontal axis displays the share of the FIs' net worth over the total net worths, and the vertical axis displays the expected default cost in the IF contract and the FE contract. The solid line, the solid line with black circles, and the dashed line display the case when the monitoring costs are the same across both the FIs and the entrepreneurs, when the FIs' monitoring cost is smaller than the entrepreneurial monitoring cost, and when the FIs' monitoring cost is larger than the entrepreneurial monitoring cost, respectively. 


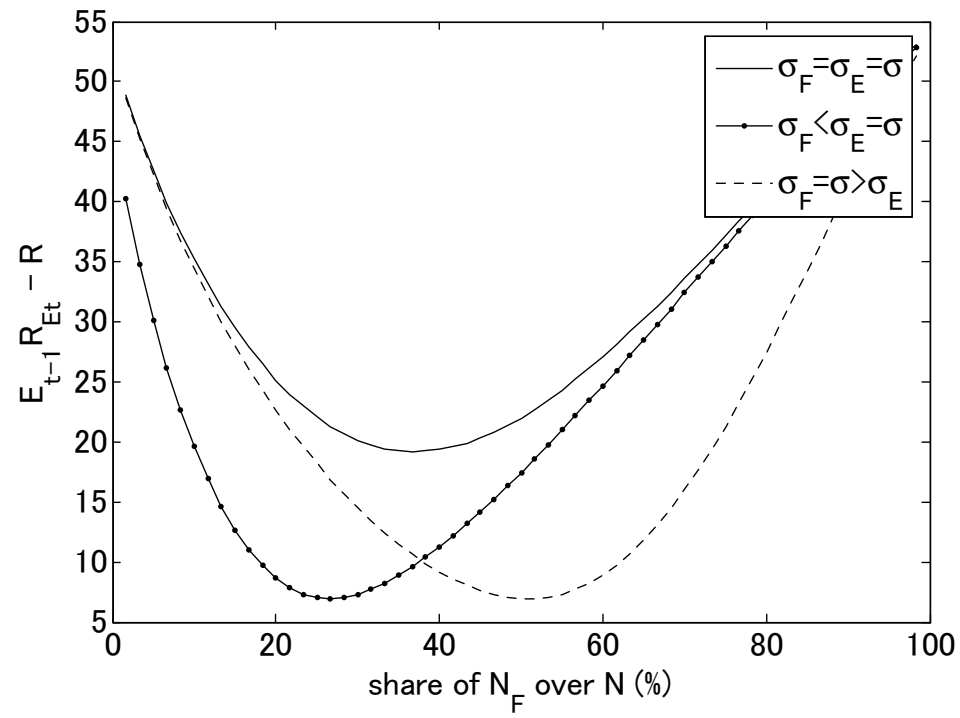

Figure 7. Effects of net worth distribution and uncertainty on the external finance premium

Note: The horizontal axis displays the share of the FIs' net worth over the total net worths, and the vertical axis displays the corresponding external finance premium. The solid line, the solid line with black circles, and the dashed line display the case when the riskiness are the same across both the FIs and the entrepreneurs, when the FIs' riskiness is smaller than the entrepreneurial riskiness, and when the FIs' riskiness is larger than the entrepreneurial riskiness, respectively. 

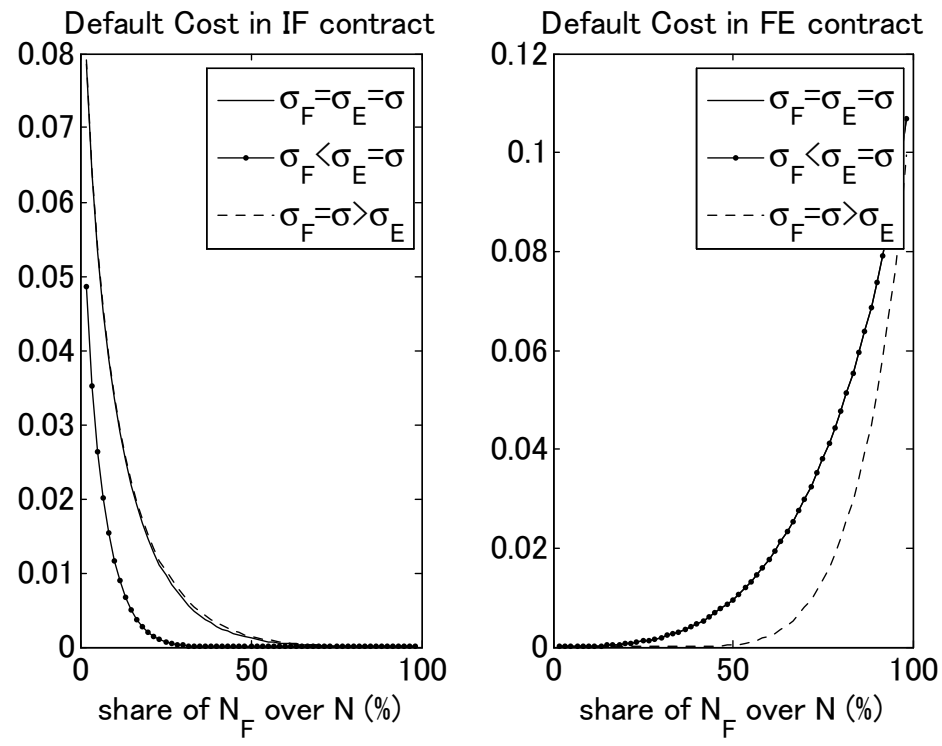

Figure 8. Effects of net worth distribution and uncertainty on default cost

Note: The horizontal axis displays the share of the FIs' net worth over the total net worths, and the vertical axis displays the expected default cost in the IF contract and the FE contract. The solid line, the solid line with black circles, and the dashed line display the case when the riskiness are the same across both the FIs and the entrepreneurs, when the FIs' riskiness is smaller than the entrepreneurial riskiness, and when the FIs' the riskiness is larger than the entrepreneurial riskiness, respectively. 


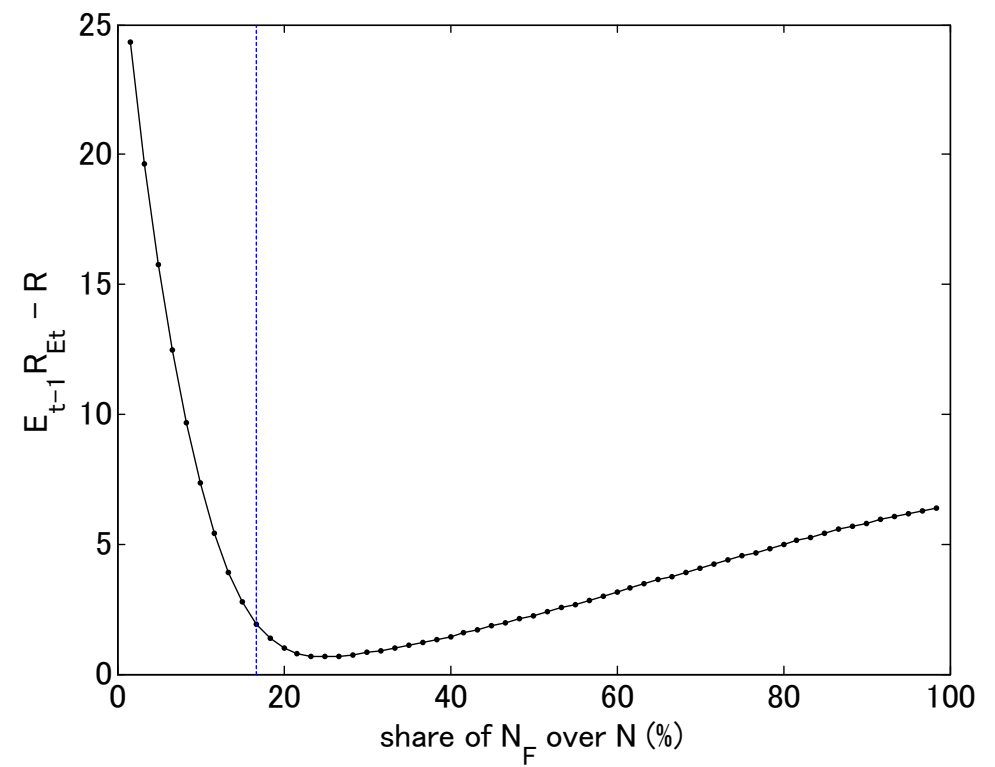

Figure 9. Effects of net worth distribution on the external finance premium in the U.S. economy

Note: The horizontal axis displays the share of the FIs' net worth over the total net worths, and the vertical axis displays the corresponding external finance premium. The dotted blue line displays the share of the FI's net worth in the U.S. economy. 

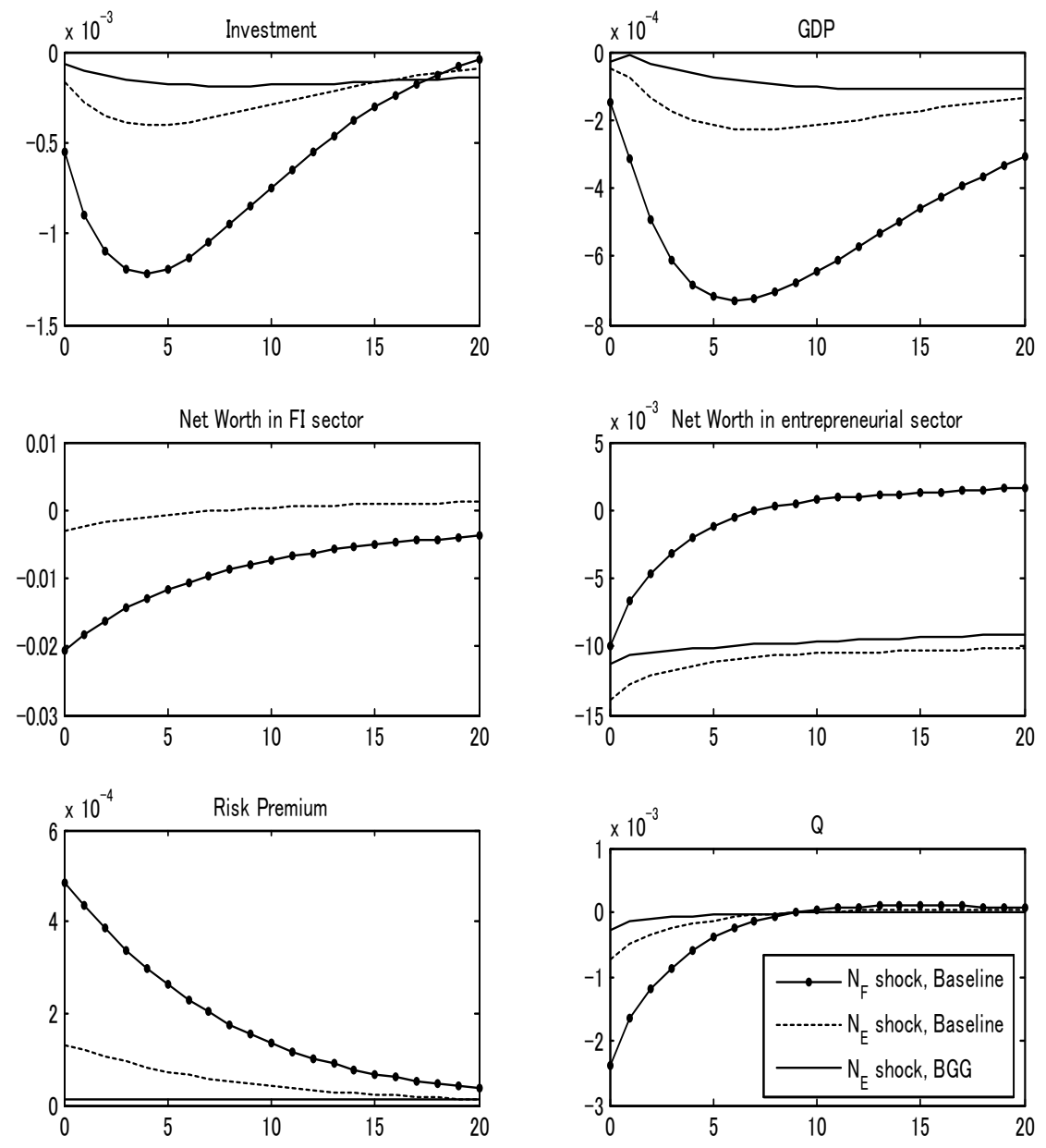

Figure 10. Impulse responses to adverse net worth shocks under the baseline model and the BGG model

Note: The solid line with black circles and the dotted line indicate the macroeconomic response to the disruption in the FIs' net worth and the entrepreneurial net worth under the baseline model. The solid line indicates the macroeconomic response to the disruption in the entrepreneurial net worth under the BGG model. 

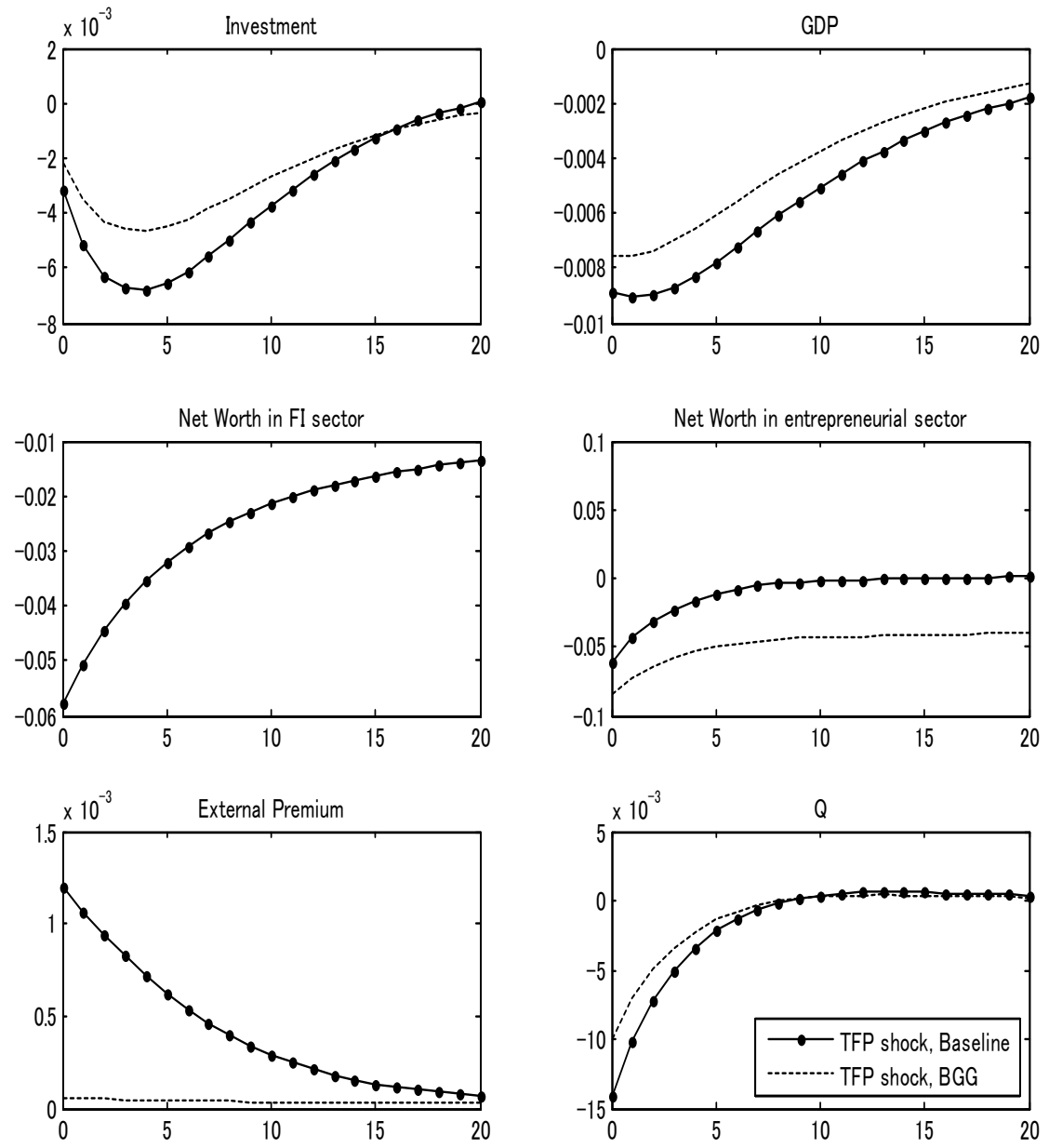

Figure 11. Impulse responses to adverse TFP shock under the baseline model and the BGG model.

Note: The solid line with black circles and the dotted line indicate the macroeconomic response to the decline in productivity under the baseline model and the BGG model, respectively. 

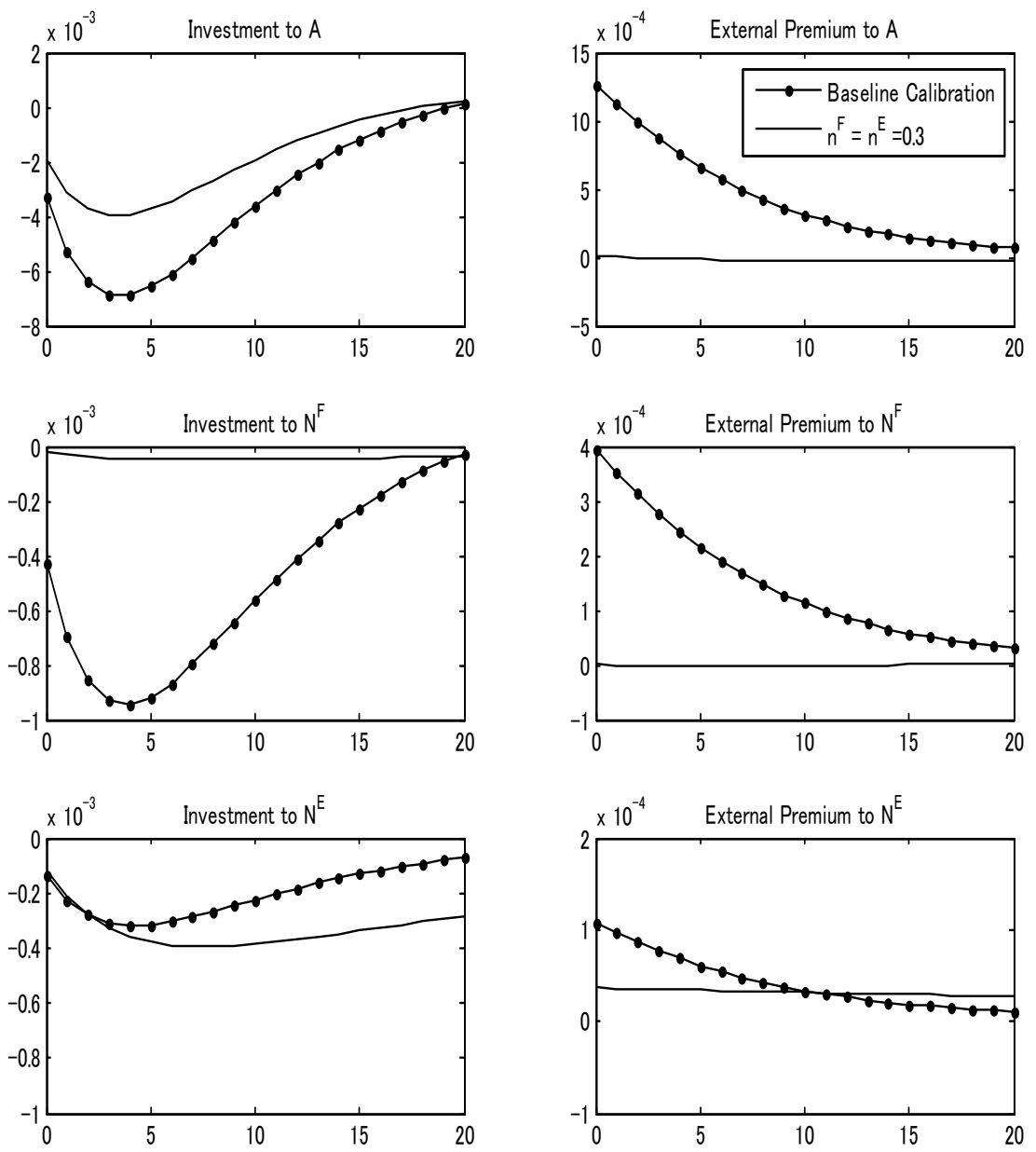

Figure 12. The role played by the cross-sectional net worth distribution in the fiancial accelerator effect.

Note: The solid line with black circles and the solid line indicate the macroeconomic response to the decline in productivity (top panel), the disruption in the FIs' net worth, and the disruption in the entrepreneurial net worth, under the baseline model and the model in which the net worth are evenly distributed across sectors. 